\title{
Balancing the Yin and Yang: TMT Gender Diversity, Psychological Safety, and Firm Ambidextrous Strategic Orientation in Chinese High-Tech SMEs
}

\author{
Shi Tang \\ University of Cambridge \\ st637@cam.ac.uk
}

Sucheta Nadkarni $\uparrow$

University of Cambridge

Liqun Wei

Hong Kong Baptist University

weiliqun@hkbu.edu.uk

Stephen X. Zhang

University of Adelaide

stephen.x.zhang@gmail.com

$†$ Sucheta Nadkarni sadly passed away before this manuscript was accepted by AMJ for publication. The author team publishes this article in Sucheta's memory.

Acknowledgements: We thank the Editor Jason Shaw and three anonymous reviewers for their developmental feedback. We would also like to thank Marian Baird, Monique

Boddington, Guoli Chen, David Harrison, Pitosh Heyden, Katherine Klein, Yasemin Kor, David Kravitz, Will Mitchell, Sabina Nielson, Lisa Nishii, Lionel Paolella, Andreas Richter, Zeki Simsek, Kulwant Singh, David Stillwell, Raymond Trau, and Maria Triana for their valuable feedback on earlier versions of the paper. The authors are also grateful for feedback from participants in the Diversity Research Publishing Workshop at the annual meetings of AOM, SMS, 2nd Workshop on Global Governance and Management. The data collection is partially supported by the Faculty Research Grant (FRG1/17-18/015) of Hong Kong Baptist University to the third author. 


\title{
Balancing the Yin and Yang: TMT Gender Diversity, Psychological Safety, and Firm Ambidextrous Strategic Orientation in Chinese High-Tech SMEs
}

\begin{abstract}
This paper offers a novel theoretical account of why and when top management team (TMT) gender diversity lends strategic advantage. Building on social role theory, we develop a moderated-mediation model showing: a) TMT psychological safety mediates the effect of TMT gender diversity on firm ambidextrous strategic orientation (ASO) (why) and b) firm slack moderates this mediated effect (when). We tested our model in the context of Chinese high-tech small- and medium-sized enterprises. After confirming gender differences in social role-based proclivities at the TMT level, a multi-wave survey study of 373 members from 120 TMTs showed that TMT gender diversity positively affects ASO via TMT psychological safety, and this mediated effect is stronger when firm slack is lower than higher. We further interviewed 23 top managers to supplement key quantitative results. Our study advances upper echelons research on TMT gender diversity in two ways. First, it highlights the genderspecific interpersonal benefit of TMT gender diversity, which is markedly distinct from the cognitive-variety argument associated generically with TMT demographic diversity. Second, it considers both men and women in TMTs in a more balanced manner, thereby offering an alternative account to the female-focused theorization of the positive strategic implications of TMT gender diversity.
\end{abstract}

\section{Keywords:}

Top management teams; gender diversity; psychological safety; social role theory; ambidexterity 
Woman is yin and man is yang. The two energies co-exist with each other.

Yin cannot exist without yang, and yang without yin. - Tao Te Ching

Redressing the imbalanced gender composition in senior leadership is taking center stage in business and policy making globally (Credit Suisse, 2019; McKinsey \& Company, 2018). Advocates of gender diversity increasingly evoke the "business case" linking a higher female percentage in top management teams (TMTs) to firm success (McKinsey \& Company, 2015, 2018). Supporting this business case, upper echelons studies have consistently found that TMT gender diversity yields strategic advantages (Dezsö \& Ross, 2012; Lyngsie \& Foss, 2017). A meta-analysis by Jeong and Harrison (2017) demonstrated that TMT gender diversity positively affects a wide range of firm performance outcomes. Despite these promising findings, existing research has relied on two problematic theoretical assumptions about the underlying mechanisms of the positive strategic effects of TMT gender diversity.

First, prior research has predominantly presumed that the benefits of TMT gender diversity accrue from a cognitive-variety mechanism — men and women bring different cognitive perspectives in TMT strategic decision-making (Dezsö \& Ross, 2012; Jeong \& Harrison, 2017; Krishnan \& Park, 2005). However, psychology research has challenged this assumption. Neuro-cognitive study and meta-analyses have shown that effect sizes of gender cognitive differences are "close-to-zero," whereas the differences in interpersonal proclivities (e.g., empathy, aggression) are generally large (Hyde, 2005: 581, 2014; Joel et al., 2015). This evidence suggests that the cognitive-variety explanation, generically applied to the effects of TMT demographic diversity, may not apply to gender. Rather, the strategic advantages of TMT gender diversity likely stem from the more pertinent, gender-specific differences in interpersonal proclivities between men and women.

Second, research has alternatively ascribed the strategic advantages of TMT gender 
diversity to female attributes (e.g., feminine leadership styles) without adequately accounting for males (Dezsö \& Ross, 2012; Lyngsie \& Foss, 2017). Gender scholars have cautioned against this female-skewed emphasis (e.g., Ali, Metz, \& Kulik, 2015) and lamented: "male is a gender too, and the field of organization studies has focused less on masculinity."

(Fernandez-Mateo \& Kaplan 2018: 1234). Relatedly, research suggests that men are essential in promoting positive gender dynamics of teams (Hoobler, Masterson, Nkomo, \& Michel, 2018). Thus, the strategic advantages of TMT gender diversity ${ }^{1}$ may not result from women alone, but from men and women working together.

To address these issues, we draw on social role theory (Eagly \& Wood, 1999) to develop a gender-specific theorization that considers both men and women. Social role theory contends that men and women hold distinct proclivities in social interactions - women are more "communal" (socially sensitive and relation-building oriented), and men are more "agentic" (assertive and voice-raising oriented) (Eagly \& Wood, 1999). At the heart of this notion, these social role-based proclivities of men and women are complementary in triggering positive interpersonal team dynamics (Bear \& Woolley, 2011; Carli, 2001), offering a compelling theoretical account of the benefits of TMT gender diversity.

Grounded in social role theory, we develop a model explaining why and when TMT gender diversity promotes a key strategic outcome — ambidextrous strategic orientation (ASO). As "the simultaneous pursuit of exploration and exploitation in firm strategic activities," ASO is increasingly considered essential for sustainable firm performance (Ou, Waldman, \& Peterson, 2018: 1153). To explicate why, we introduce TMT psychological safety as a central mechanism transmitting the unique interpersonal benefit of TMT gender

\footnotetext{
${ }^{1}$ In this study, we use gender diversity to indicate a continuous degree of gender variety in TMTs, with the highest degree capturing a gender balance - the equal representation of male and female members.
} 
diversity to ASO. Adapting from Edmondson (1999), we refer to TMT psychological safety as the shared belief of TMT members that the team is safe for interpersonal risk-taking such as openly raising controversial issues and challenging each other. In addition, we specify a relevant boundary condition—firm slack resources (Simsek, Veiga, \& Lubatkin, 2007)— to deepen our understanding of when the positive effect of TMT gender diversity on ASO via TMT psychological safety will be stronger or weaker.

Our paper offers a novel theoretical account of the strategic advantage of TMT gender diversity in two ways. First, we underscore its unique interpersonal underpinnings. As one of the first to link gender diversity to psychological safety, our theoretical mechanism is markedly distinct from the cognitive-variety argument applied generically to TMT demographic diversity. We challenge the dominant assumption that gender diversity functions equivalently to other demographic proxies (e.g., tenure, education, functional background) of TMT cognitive variety. Second, by highlighting the complementary social-role proclivities of both male and female members in promoting TMT psychological safety and in turn ASO, we offer an alternative account to the prevalent female-focused theorization of the positive strategic implications of TMT gender diversity.

\section{THEORETICAL BACKGROUND}

\section{Gender Differences in Interpersonal Proclivities: Social Role Theory}

As one of the "grand theories" of gender in psychology (Hyde, 2014), social role theory has been cross-culturally validated in explaining gender differences in social behaviors (Wood \& Eagly, 2002). It contends that biological differences between men and women (e.g., men's greater physical strength and women's capacity to bear and nurse children) allow certain labor activities to be more efficiently accomplished by one gender than the other; the resultant societal labor division distributes men and women into different social roles-men 
as "resource providers" and women as "homemakers" (Eagly \& Wood, 1999). Gender differences derived from these distinct social roles are characterized as agentic versus communal — more agentic for men (assertive, ambitious and voice-oriented) and more communal for women (socially sensitive, empathetic and relation-oriented) (Eagly, 1987).

Over time, men and women accommodate themselves to these social-role attributes that reflect the society's shared beliefs and expectations (Eagly \& Karau, 2002). For instance, the importance of close relationships designated by communality favors women's acquisition of relational facilitative skills; the agentic attributes ascribed to men promote a pattern of assertive behaviors such as speaking assertively and giving directions (Wood, Christensen, Hebl, \& Rothgerber, 1997). These gender-differentiated beliefs and expectations also constitute the self-concepts of men and women that shape their social proclivities (Witt \& Wood, 2010). Thus, through both social- and self-regulation, men and women internalize social role-based differences and consciously or unconsciously exhibit role-consistent behaviors (Eagly, 2018).

Social role theory acknowledges that job roles may constrain gender-differentiated behaviors, e.g., women in male-stereotyped leadership roles may behave more agentically than women in some other jobs (Eagly \& Karau, 2002). However, scholars have emphasized that "gender roles ordinarily continue to have some impact on behavior, even in the presence of specific (job) roles" (Eagly \& Wood, 1999: 413). Indeed, research has found that gender is a chief driver of communal versus agentic behaviors in the workplace (Moskowitz, Suh, \& Desaulniers, 1994). Men and women carry social-role differences even to the senior executive level (Eagly, Johannesen-Schmidt, \& Van Engen, 2003; Oakley, 2000). A metaanalysis by Eagly et al. (2003) confirmed that female leaders (including senior executives) are more sensitive to and considerate of others' needs, whereas their male counterparts are 
more inclined to challenge others and give directions. Recent surveys of past and present CEOs of Fortune 1000 companies have also revealed that female CEOs are more concerned about others' self-worth, appreciate others' contributions and emphasize trust-building more than male CEOs (Orr \& Stevenson, 2017; Sawdye, 2017).

Research in the tradition of social role theory has established that these gender differences in the interpersonal proclivities of men and women manifest themselves in team interactions (Wood, 1987; Woolley, Chabris, Pentland, Hashmi, \& Malone, 2010). Female members are more socially sensitive than males - they better perceive, understand, and respect the feelings of other team members (Post, 2015). Conversely, men have a greater voice-raising tendency than women - they are much more likely to challenge others, raise controversial issues and speak up openly in the team (LePine \& Van Dyne, 1998). Scholars have further argued that these social-role proclivities are complementary in cultivating positive interpersonal team dynamics in gender-diverse teams (Bear \& Woolley, 2011; Carli, 2001). Relatedly, research has shown that the more equal representation of men and women in teams improves team performance (Wegge, Roth, Neubach, Schmidt, \& Kanfer, 2008).

In sum, social role theory offers a powerful gender-specific lens to explain the strategic advantages of TMT gender diversity found consistently in upper echelons studies (Dezsö \& Ross, 2012; Jeong \& Harrison, 2017; Krishnan \& Park, 2005; Lyngsie \& Foss, 2017). It highlights gender differences in interpersonal proclivities and their complementarity in team interactions. Based on these key notions, we introduce TMT psychological safety as a central mechanism that transmits the interpersonal benefits of TMT gender diversity.

\section{TMT Psychological Safety: A Unique Interpersonal TMT Dynamic}

Early studies regarded psychological safety as an individual's sense of being authentic "without fear of negative consequences to self-image, status or career" (Kahn, 1990: 708). 
This research demonstrated the critical role of psychological safety in enabling individuals to feel secure and to overcome defensiveness or anxiety when encountering errors and contradictions at work (Brown \& Leigh, 1996). Subsequently, Edmondson (1999) developed the construct of team psychological safety to capture team members' shared belief about whether the team is safe for taking interpersonally threatening actions such as openly raising controversial issues and challenging others. Distinct from the individual-level phenomenon, team psychological safety "must characterize the team rather than individual members of the team" (Edmondson, 1999: 354). Scholars have argued that because members are exposed to the same team interaction (e.g., observing other members speaking up) and structural influences (e.g., team task), team psychological safety should develop through interactions among team members and converge in the team (Cronin, Weingart, \& Todorova, 2011; Edmondson, 1999; Schulte, Cohen, \& Klein, 2012).

In essence, team psychological safety contains two equally important interpersonal components. First, there is a relational component of mutual trust and support reflecting the shared belief that team members respect and support each other's divergent needs, interests, and vulnerabilities (Edmondson, 1999). Second, there is a voice-raising component, i.e., interpersonal risk-taking, capturing the belief that it is safe for members to openly speak up and challenge others without being judged or socially distanced (Detert \& Edmondson, 2011). These two aspects are intertwined and operate together to form a team's psychological safety — only when members mutually trust and support each other will they all openly speak up without fearing adverse interpersonal consequences (Edmondson, 2003). As a constructive interpersonal team dynamic, team psychological safety facilitates various team outcomes such as timely problem detection, better goal achievement, and superior team performance (Edmondson \& Lei, 2014). 
Building on the team-level conceptualization of psychological safety (Edmondson, 1999), we introduce TMT psychological safety as a crucial dynamic in the TMT context. The dual focus of psychological safety makes it conceptually distinct from other TMT interpersonal dynamics including social cohesion (Smith et al., 1994), behavioral integration (Simsek, Veiga, Lubatkin, \& Dino, 2005), and conflict (Amason, 1996). Both TMT social cohesion and behavioral integration overlook the notion of interpersonal risk-taking. As Edmonson (1999: 354) stressed, psychological safety captures "neither a careless sense of permissiveness, nor an unrelentingly positive affect" but "a sense of confidence" of members to speak up and challenge others. On the other hand, TMT (affective) conflict highlights personal disputes and negative sentiments among members without mutual trust and support (Amason, 1996). Capturing both a relational (mutual trust and support) and a voice-raising (taking interpersonal risks to openly speak up) aspect, the concept of TMT psychological safety can offer unique insights into how TMT dynamics foster important firm strategies.

We argue that the dual focus of team psychological safety reflects the essence of the complementarity between the social-role proclivities of men and women. Women's social sensitivity in understanding and respecting others' feelings promotes close relational bonds as well as others' willingness to reciprocate trust and support (Williams \& Polman, 2015). Men's voice-raising tendency acts as an exemplar in the team to openly speak up, raise controversies, and challenge others (LePine \& Van Dyne, 1998, 2001). Thus, gender diversity in TMTs likely sets in motion the two intertwining aspects of TMT psychological safety, which further influences a key firm outcome - ambidextrous strategic orientation (ASO).

\section{Ambidextrous Strategic Orientation (ASO)}

Because TMT psychological safety enables members to openly raise controversial issues and challenge each other in a trusting and supportive manner for strategic decision-making, it 
is likely to benefit firm strategic orientation at large. Within the broad outline of strategic orientation (Slater, Olson, \& Hult, 2006), ASO is a particularly relevant and important outcome. It denotes the simultaneous pursuit of exploitative and explorative strategies in firms (Ou et al., 2018). Central to both survival and long-term performance, ASO helps firms avoid the competency trap from an exclusive focus on exploitation and the failure trap caused by an overemphasis on exploration (March, 1991). As a crucial means of sustaining competitive advantage, ASO has been increasingly regarded as an important firm outcome in strategy research (Heavey \& Simsek, 2017; Ou et al., 2018).

The reasons that we choose to work on ASO, a pertinent strategic orientation driven by TMT psychological safety, are twofold. First, although simultaneously pursuing exploitation and exploration helps firms gain competitive advantage, they are contradictory at large (He \& Wong, 2004). Exploitation focuses on refining prior competencies, meeting existing environmental needs, and enhancing reliability, whereas exploration stresses experimentation, discovering new possibilities, and increasing variation (March, 1991). The exploitationexploration conflict and ambiguity inherent in ASO create considerable interpersonal tensions in TMTs (Lubatkin, Simsek, Ling, \& Veiga, 2006; Ou et al., 2018), which can largely benefit from the interpersonally constructive dynamic of TMT psychological safety.

Second, ambidexterity scholars have compared ASO to "the yin and yang of continuous self-renewal" and stressed that its attainment necessitates a balance between soft (yin) and hard (yang) elements in organizations (Gibson \& Birkinshaw, 2004: 213; also see Ghoshal \& Bartlett, 1997). The hard element reflects a task or performance orientation that encourages organizational actors to "push for ambitious goals," whereas the soft element denotes a relational basis that ensures "this happens within a cooperative environment" (Gibson \& Birkinshaw, 2004: 213). We argue that the dual focus of TMT psychological safety embodies 
a soft-hard balanced TMT dynamic: its relational component of mutual trust and support captures the essence of the soft, and its voice-raising component fulfills the functionality of the hard. This soft-hard balance embedded in TMT psychological safety is essential for facilitating ASO.

\section{HYPOTHESIS DEVELOPMENT}

Integrating social role theory with the psychological safety and upper echelons literature, we develop a moderated-mediation model (Figure 1) that explains why and when TMT gender diversity relates to ASO. We hypothesize TMT psychological safety as a central mediator in the relationship between TMT gender diversity and ASO (why), and firm slack as a boundary condition (when) moderating this mediated effect.

Insert Figure 1 about here

\section{TMT Gender Diversity and Psychological Safety}

Research grounded in social role theory points to the positive interpersonal dynamic of gender-diverse teams in two related ways. First, more equal representation of men and women reinforces a broader range of acceptable behaviors in the team, where both genders can more freely express their interpersonal proclivities (Kanter, 1977). Particularly in traditionally male-dominated senior leadership teams, gender diversity reduces the pressure that women face to "act like men" and enables them to openly express their communal proclivities such as being empathetic and caring about others' feelings (Ely, 1995: 621). Second, "a balanced number of different genders helps fully reap the benefits of gender diversity" because it allows men and women to shape the overall team dynamic more equally (Lee, Choi, \& Kim, 2018: 189). When there are fewer women in a team, they are more likely to get marginalized into tokens with little influence on team interactions (Kanter, 1977; 
Torchia, Calabrò, \& Huse, 2011). Similarly, when women are in the majority, men get undermined because women form allies and exert greater influence in the team (Berdahl, 2007; Carli, 2001; Eriksen \& Einarsen, 2004). Thus, greater gender diversity is essential to reduce tokenism and allow both men and women to more equally shape the team dynamic.

Building on the above, we argue that more gender-diverse TMTs will enable both genders to infuse their social-role proclivities more freely and equally in TMT interactions, which complement each other to enhance TMT psychological safety. Research indicates that women's social sensitivity makes controversies, debates, and disagreements in teams occur in more supportive and trusting manners (Post, 2015; Woolley et al., 2010). Scholars have further shown that men exhibit more respectful, caring, and considerate behaviors when there are proportionally more women present (Lee et al., 2018; Williams \& Polman, 2015). Meanwhile, men's voice-raising tendency encourages team members to openly challenge each other and discuss controversial issues, thereby preventing excessive consensus seeking in the team (Edmondson, 2002; LePine \& Van Dyne, 2001). Especially when women observe men voicing authentic and controversial thoughts without getting socially punished, they are more likely to feel comfortable raising their own voices in the TMT. In sum, the equal infusion of men's and women's social-role proclivities in TMTs, enabled by gender diversity, will foster TMT psychological safety that characterizes both mutual trust and support, and interpersonal risk-taking to openly speak up.

In some cases, individuals may hold interpersonal proclivities counter to their conventional social roles, such as women having high voice-raising tendencies and men being highly socially sensitive (Moss-Racusin, Phelan, \& Rudman, 2010; Rudman \& Glick, 1999). When these individuals express their role-inconsistent proclivities, they often receive backlashes and negative judgments. Research has found that female leaders encounter 
reduced likability for their agentic behaviors (Heilman \& Okimoto, 2007). Similarly, when men behave communally such as being socially warm and supportive, they suffer from prejudice and are viewed as weak (Rudman \& Mescher, 2013). As a safeguard against these detrimental interpersonal consequences, TMT psychological safety stemming from gender diversity allows all members to freely express their authentic proclivities, which reinforces the constructive interpersonal dynamic in the TMT.

In contrast, less gender-diverse TMTs are likely to hinder the equal infusion of social sensitivity and voice-raising tendencies in team interactions. Female-majority teams often overemphasize the communality while suppressing the agentic orientation of team dynamics (Apesteguia, Azmat, \& Iriberri, 2012; Post, 2015). In such TMTs, as men who are in the minority perceive disagreeing with or challenging others as inconsistent with the dominant communal team dynamic, they may not feel comfortable in candidly expressing controversial or divergent opinions. This skewed team dynamic toward social sensitivity without voiceraising is counter to TMT psychological safety (Edmondson, 1999). Conversely, maledominated TMTs tend to overemphasize voice raising at the cost of social sensitivity. When members challenge each other and raise controversial issues without mutual trust and support, the team dynamic devolves into overt competition, aggressiveness, and conflict (Lee et al., 2018; LePine, Hollenbeck, Ilgen, Colquitt, \& Ellis, 2002). This team dynamic lacking mutual trust and support also runs counter to TMT psychological safety (Edmondson, 1999).

H1: TMT gender diversity is positively related to TMT psychological safety.

\section{TMT Psychological Safety and ASO}

Scholars have argued that there are two core tasks for TMTs to effectively manage ASO (Heavey \& Simsek, 2017). First, TMTs need to differentiate between explorative and exploitative strategies as they entail distinct supporting resources, organizational 
competencies, and market opportunities (Smith \& Tushman, 2005). By clearly demarcating them, TMTs can strategically separate the two sets of activities and provide the infrastructure essential to address their distinct demands; failure to do so would result in a single-minded explorative or exploitative orientation of firms (Andriopoulos \& Lewis, 2009). Second, TMTs need to further integrate exploration and exploitation by identifying or creating synergies, complementarities, and interdependencies between them (Heavey \& Simsek, 2017). Without integration, exploration and exploitation would become fragmented strategies, leading to role conflicts, coordination gaps, and misuse of resources (Smith \& Tushman, 2005).

Each of the two ASO tasks, however, involves substantial interpersonal tensions in TMTs (Lubatkin et al., 2006; Ou et al., 2018). We argue that TMT psychological safety, as a softhard balanced dynamic, is key to addressing these interpersonal challenges (Gibson \& Birkinshaw, 2004). First, the need to differentiate requires TMT members to openly express and articulate their own strategic interests in exploration or exploitation (Smith \& Tushman, 2005). Yet, as the strategic demands from explorative and exploitative activities are often contradictory, TMT members holding different orientations tend to be reluctant to openly express opinions in front of each other due to fear of backlashes (Jansen, Tempelaar, Van den Bosch, \& Volberda 2009). For example, a TMT member heading an explorative unit or project may hesitate to openly voice ideas on emerging business opportunities and ways to disrupt existing business functions, given the fear that these ideas would threaten members heading exploitative activities, and vice versa (Heavey \& Simsek, 2017).

By ensuring mutual trust and support in the team, TMT psychological safety can alleviate members' concerns about negative interpersonal consequences and therefore promote their willingness to voice authentic interests in exploration or exploitation 
(Kostopoulos \& Bozionelos, 2011). In the meantime, by facilitating interpersonal risk-taking to openly speak up, TMT psychological safety can encourage members to elaborate on their explorative or exploitative ideas, even though these ideas may appear controversial to members preferring opposite orientations (Gong, Cheung, Wang, \& Huang, 2012). As a result, as all TMT members engage in open and candid communications about their different strategic interests based on trusting and supportive relations, the whole TMT can better differentiate the environmental demands, resource requirements, and action plans associated with exploration and exploitation strategies (Cao, Simsek, \& Zhang, 2010).

Second, TMT members heading different units or activities must engage in close collaboration and mutual problem-solving (Jansen, George, Van den Bosch, \& Volberda, 2008) to integrate exploration and exploitation. However, TMT members often focus on the explorative or exploitative goals and agendas of their own units, "individually as senior executives" rather than collectively as a team (Lubatkin et al., 2006: 650). As a result, they tend to be indifferent to each other's strategic interests or even hostile to those who hold conflicted orientations as they compete for limited resources (Mihalache, Jansen, Van den Bosch, \& Volberda, 2014). Such indifference and animosity create a major interpersonal barrier in TMTs to achieving the integration task of ASO (Ou et al., 2018).

With mutual trust and support, TMT psychological safety can motivate members to genuinely accept and accommodate the different resource and competence requirements for others' exploration or exploitation goals (Jansen et al., 2008). This therefore prevents members from ignoring others' strategic interests or from exercising expert authority upon each other in order to pursue their preferred strategic agendas (Mihalache et al., 2014). Meanwhile, TMT psychological safety can also encourage TMT members to voice critical but constructive feedback and openly discuss controversies arising from simultaneously 
pursuing exploration and exploitation. Research suggests that such feedback processes are crucial for synthesizing different viewpoints (Tushman \& Nadler, 1978) and for finding creative ways to build linkages between exploration and exploitation (Ou et al., 2018).

H2: TMT psychological safety is positively related to ASO.

\section{The Mediating Role of TMT Psychological Safety}

The upper echelons perspective asserts that the internal TMT dynamic is a central means through which TMT diversity shapes firm strategies (Carpenter, Geletkanycz, \& Sanders, 2004; Finkelstein, Hambrick, Cannella, 2009). Accordingly, we build on H1 and H2 to posit that the interpersonal benefit of TMT gender diversity will be transmitted into ASO through TMT psychological safety. In more gender-diverse TMTs, the complementarity between women's social sensitivity and men's voice-raising tendency will foster members' mutual trust and support, and interpersonal risk-taking to speak up. In turn, these two essential elements of TMT psychological safety reflect a soft-hard balanced TMT dynamic, which enables the team to effectively resolve the interpersonal tensions involved in differentiating and integrating exploration and exploitation for attaining ASO.

H3: TMT psychological safety mediates the positive relationship between TMT gender diversity and firm ambidextrous strategic orientation.

\section{The Moderating Role of Firm Slack Resources}

The influence of TMTs on firm strategies is often bounded by contextual conditions (Bromiley \& Rau, 2016; Carpenter et al., 2004). In particular, upper echelons scholars have highlighted that the strategic advantages of constructive TMT dynamics become especially prominent when firms are in resource-constrained conditions (Finkelstein et al., 2009;

Turturea, Jansen, \& Verheul, 2015). This is because when resources are scarce, TMTs need to rely more on their attributes and dynamics to "bootstrap their limited resources" (George, 2005: 664) or even "create something from nothing" (Baker \& Nelson, 2005: 329). Team 
research similarly indicates that team psychological safety is particularly crucial in resourceconstrained settings (Tucker \& Edmondson, 2003; Weiss, Hoegl, \& Gibbert, 2011). For example, Nembhard and Edmondson (2006) showed that in healthcare teams, where resources are usually insufficient and members are "stretched thin," psychological safety is essential for overcoming teams' reluctance to engage in collaborative learning.

Building on the above, we propose firm slack - the firm resources that are "unfettered, uncommitted, and therefore available for discretionary use" (Simsek et al., 2007: 1398) — to be a key boundary condition for the mediated effect of TMT psychological safety. Specifically, we expect that the lack of firm slack (slack scarcity) will amplify both stages of the positive mediation of TMT psychological safety: a) from TMT gender diversity to TMT psychological safety and b) from TMT psychological safety to ASO.

First, slack scarcity acts as pertinent adversity to TMTs by not only disadvantaging flexible resource allocation but also making firms vulnerable to environmental changes (Haleblian, McNamara, Kolev, \& Dykes, 2012). Social-role research suggests that adverse situations press men and women to behave in more role-congruent ways (Eagly \& Karau, 2002; Moskowitz et al., 1994). In particular, studies have shown that adversity induces men to engage more in voice raising (De Clercq \& Belausteguigoitia, 2017) and women to exert more relational behaviors (Post, Latu, \& Belkin, 2019), to counteract the adversity. Therefore, we argue that when gender-diverse TMTs confront the slack resource adversity, men tend to infuse greater voice-raising tendencies to facilitate members in more openly expressing their opinions, even provocative ones, to change the status quo (Simsek et al., 2007). Similarly, trusting and supportive relations become more critical for TMT members to cope with adversity and crises together (Carmeli, Tishler, \& Edmondson, 2012). Thus, female members tend to infuse greater social sensitivity to foster stronger relational bonding in the TMT. In 
sum, slack scarcity is likely to press gender-diverse TMTs to better leverage members' complementary interpersonal proclivities to develop higher TMT psychological safety.

Second, we argue that slack scarcity can also render the interpersonal tensions in TMTs more salient in the pursuit of ASO, which makes TMT psychological safety even more essential for overcoming these interpersonal challenges. When slack is scarce, TMTs are more concerned about potential losses from failures due to the lack of financial buffers (Haleblian et al., 2012). As a result, members' different opinions and ideas about exploration and exploitation will appear more threatening to each other, and openly raising voices would involve higher interpersonal risks (Wilhelm, Richter, \& Semrau, 2019). Moreover, because slack scarcity prevents TMTs from supporting more projects and strategic activities, it exacerbates the interpersonal conflicts among members vying for limited resources (Jansen, Simsek, \& Cao, 2012). By providing strong built-in safeguards against these interpersonal risks and conflicts, TMT psychological safety will matter more in enhancing ASO when slack is scarce than when it is abundant (Lubatkin et al., 2006). Taken together, we propose:

H4: The strength of the mediated effect of TMT gender diversity on firm ambidextrous strategic orientation via TMT psychological safety varies along the degree of firm slack, such that the mediated effect will be stronger when firm slack is lower than higher.

\section{METHODS}

\section{Chinese High-Tech SME Context}

Our empirical setting is SMEs in high-tech industries in China. Several criteria guided this choice. First, with the proportion of women in TMTs averaging 24 percent globally (Grant Thornton, 2017), examining the strategic implications of equal male and female TMT representation in field settings is a major challenge. However, China has been reported to have the highest female proportion (51\%) in senior executive teams among 44 countries (Grant Thornton, 2013). This considerably higher female representation makes China a 
particularly suitable context to test our gender balance-based contentions in TMTs.

Second, the pursuit of ASO is often crucial for firms in high-tech industries (Lubatkin et al., 2006). Adapting to rapid market changes requires high-tech firms to engage in a series of quick adjustments to exploit existing opportunities, while major shifts in technologies and competitive boundaries also require firms to concurrently explore new products/services and markets (Cao, Gedajlovic, \& Zhang, 2009; He \& Wong, 2004).

Finally, because SMEs have flatter structures with less horizontal and vertical structural segregation between exploration and exploitation activities, TMTs play a more direct role in managing ASO (Heavey \& Simsek, 2017; Ou et al., 2018). Thus, SMEs provide a suitable context for investigating the influence of TMT characteristics (gender diversity) and dynamics (psychological safety) on shaping ASO.

\section{Sample and Data Collection}

We collected multi-wave survey data from privately held high-tech SMEs in four major cities of China-Beijing (north), Guangzhou (south), Shanghai (east) and Chengdu (west)— representing a geographic microcosm. These cities also serve as leading high-tech hubs of China (Zhu, 2017). We obtained lists of firms compiled by the administrative offices of science parks and high-tech industry zones in these cities. We identified firms that satisfied two widely accepted criteria of SMEs: fewer than 500 employees and more than six years old (Chen \& Nadkarni, 2017; Zahra, Ireland, \& Hitt, 2000). Following previous TMT survey studies of Chinese high-tech SMEs (Qian, Cao, \& Takeuchi, 2013), we hired and trained research assistants from local administrative offices to deliver our surveys. Because these local officers often personally know the TMT members of firms within their areas, and such personal relations are highly valued in the Chinese culture, their assistance has been shown to effectively boost response rates (Chen \& Nadkarni, 2017; Qian et al., 2013). 
Before the main study, we conducted a validation study on the existence of gender differences in the social-role interpersonal proclivities in our target population. Although the meta-analysis by Eagly et al. (2003) confirmed that social role-based gender differences apply to organizational leaders (including senior executives), some scholars have contended that women might need to behave incongruently with their communal proclivities for their senior leadership roles (Brescoll, 2016). Our validation study based on a sample of 219 top managers demonstrated that TMT members of Chinese high-tech SMEs maintain the theorized gender differences (see Appendix I for details of the validation study). This evidence lends further credence to our core contentions grounded in social role theory.

In the main study, the research assistants contacted the CEOs of 450 randomly sampled SMEs via phone or on-site visits to seek participation, and 172 of them agreed to participate. Following established practices, we asked the CEOs to identify TMT members-top executives who report directly to the CEO and play a central role in strategic decisionmaking (Chen \& Nadkarni, 2017; Ling, Simsek, Lubatkin, \& Veiga, 2008). Upper echelons research has asserted that CEOs are a key and reliable source for identifying the TMT composition of their firms (Carpenter et al., 2004).

We created the original surveys in English and translated to Chinese following the backtranslation practice (Brislin, 1980). We piloted the surveys with 10 top managers (not in the sample). The surveys were administered at three time periods to all TMT members (including CEOs). The first survey ( $\mathrm{t} 1$ ) measured demographics, firm slack, and controls. Two weeks later (t2), the second survey on TMT psychological safety was distributed. Following prior research, we obtained ASO ratings from TMTs about one year later (t3) (Heavey \& Simsek, 2017). Scholars have shown that subjective measures from TMTs are as reliable and valid as objective firm measures because TMTs are knowledgeable informants of their firm strategies 
(Dess \& Robinson, 1984; Wall et al., 2004). Temporal separations between multiple survey waves helped reduce the common method bias and strengthened the directionality of proposed relationships (Podsakoff, MacKenzie, Lee, \& Podsakoff, 2003).

We retained firms with complete responses from at least three TMT members (including CEOs) across all time periods. The final sample comprised 373 TMT members of 120 firms. The effective response rate of 27 percent is comparable to the response rates $(19 \%-37 \%)$ reported in previous multi-wave survey research of TMTs in SMEs (Chen \& Nadkarni, 2017; Lubatkin et al., 2006). The average TMT size was 4.38 members with an average 71 percent intra-team response rate, and there was no significant difference in response rates between female and male TMT members $(t=-.10$, n.s. $)$. The percentage of female members ranged from 0 to 100 and averaged 43 percent. We found no significant difference in CEO gender $(t$ $=1.08$, n.s. $)$ or firm age $(t=1.13$, n.s. $)$ between the responding and nonresponding firms.

\section{Measures}

TMT gender diversity. We calculated TMT gender diversity using Blau's (1977) index (1 - $\sum P_{i}^{2}$, where $P$ is the proportion of members in a specific gender category; and $i$ represents the number of categories). Blau's index is considered the most suitable to capture team diversity on categorical attributes including gender diversity (Harrison \& Klein, 2007; Joshi $\&$ Roh, 2009). It is a continuous measure ranging from 0 (same-gender teams) to .50 (genderbalanced teams with equal female and male proportions), and the Blau's index in our sample spanned the entire feasible range of TMT gender diversity: 0 to .50 . Consistent with our theorization, Blau's index allows the effects of TMT gender diversity to be symmetric (Harrison \& Klein, 2007) regardless of female- or male-majority teams. Thus, it essentially captures the degree of gender balance in TMTs.

The computation of TMT gender diversity includes the gender $(1=$ female, $0=$ male $)$ of 
the CEO and all TMT members. Upper echelons scholars have stressed that the CEO is an integral part of the TMT (Finkelstein et al., 2009; Hambrick, 2007; Nadkarni \& Herrmann, 2010), and hence research has consistently included CEOs in the measure of TMT gender diversity (Dezsö \& Ross, 2012; Jeong \& Harrison, 2017; Lyngsie \& Foss, 2017).

TMT psychological safety. We measured TMT psychological safety using the 7-item scale of Edmondson (1999) $(\alpha=.78)$. Sample items include "Team members are able to bring up problems and tough issues" and "It is safe to take a risk on this team" (from $1=$ strongly disagree to $7=$ strongly agree). The good interrater agreement $\left(\right.$ mean $r_{w g(j)}=.97$, ICC $[1]$ $=.39, \operatorname{ICC}[2]=.66)$ and between-team variance by one-way $\operatorname{ANOVA}(\mathrm{F}=5.49, p<.01)$ justified aggregation of the individual ratings to the team level (Bliese, 2000; LeBreton \& Senter, 2008). The team aggregation of TMT psychological safety is consistent with its conceptualization as an "emergent construct," which derives from the perception of individual members but converges and manifests itself at the team level (Cronin et al., 2011: 574), and it has been consistently used in team psychological safety research (e.g., Edmondson, 1999; Schulte et al., 2012; Wilhelm et al., 2019).

Ambidextrous Strategic Orientation (ASO). We measured ASO using the 8-item scale by He and Wong (2004) $(1=$ strongly disagree to $5=$ strongly agree). Four items capture the exploration orientation (e.g., introduce new generation of products) $(\alpha=.81)$ and four items capture exploitation (e.g., improve existing product quality) $(\alpha=.78)$. Aggregations were justified (exploration: mean $\mathrm{r}_{w g(j)}=.93$; ANOVA $F=4.86, p<.01 ; \operatorname{ICC}[1]=.36$, ICC [2] $=.62$; exploitation: mean $\left.\mathrm{r}_{w g(j)}=.92 ; \operatorname{ANOVA} F=3.64, p<.01 ; \operatorname{ICC}[1]=.35, \operatorname{ICC}[2]=.61\right)$. Following prior research (Lubatkin et al., 2006), confirmatory factor analysis (CFA) showed that the two-factor structure of exploration and exploitation $\left(\chi^{2}=45.56\right.$, Prob $>\chi^{2}=.00$, CFI $=.93, \mathrm{TLI}=.90, \mathrm{RMSEA}=.10, \mathrm{SRMR}=.06)$ had a significantly stronger model fit than the 
one-factor model $\left(\chi^{2}=72.99\right.$, Prob $>\chi^{2}=.00, \mathrm{CFI}=.86, \mathrm{TLI}=.80, \mathrm{RMSEA}=.15$, SRMR $=.07)$ based on the chi-square difference test $\left(\Delta \chi^{2}=27.33, p<.01\right)$.

Consistent with the conceptualization of ASO as the simultaneous pursuit of exploration and exploitation, we used the combined magnitude of exploration and exploitation, with higher levels of both indicating higher ASO (Cao et al., 2009). We multiplied the exploration and exploitation scores to create a single index of ASO (He \& Wong, 2004) — the most widely used measure of ambidexterity according to the review by Birkinshaw and Gupta (2013). Additionally, we confirmed the robustness of our results using an additive index (the sum of exploration and exploitation scores) (Heavey \& Simsek, 2017).

Firm slack. We adopted Simsek et al. (2007)'s 4-item scale ( 1 = strongly disagree, $5=$ strongly agree) to measure firm slack $(\alpha=.73)$. An example item was "Our firm has plentiful resources to produce our products and/or services." Researchers have stressed that firm slack can be appropriately measured by the ratings from TMT members, as they are knowledgeable informants of their firms' level of slack resources (Simsek et al., 2007). The aggregation of TMT members' ratings to reflect the firm-level slack was justified (mean $r_{w g(j)}=.95$, ANOVA $\mathrm{F}=4.96, p<.01 ; \operatorname{ICC}[1]=.54, \operatorname{ICC}[2]=.78)$. This scale has been widely used to measure discretionary slack, especially by studies on ambidexterity in SMEs (Lubatkin et al., 2006; Simsek et al., 2007).

Controls. Following recommendations for control variable selection ${ }^{2}$ (Becker et al., 2016; Carlson \& Wu, 2012), we included several controls. First, to isolate the effects of TMT gender diversity from other forms of demographic heterogeneity that have been regarded as

\footnotetext{
${ }^{2}$ Based on the recommended practices for control variable (CV) selection (Becker et al., 2016; Carlson \& Wu, 2012), we followed five key steps to include CVs: 1) reviewing CV zero-order correlations, 2) excluding impotent and theoretically unjustifiable CVs, 3) explaining the theoretical relevance and operationalization of included CVs, 4) reporting descriptive data for the CVs, and 5) interpreting the $\mathrm{CV}$ results.
} 
proxies of cognitive variety, we controlled for TMT heterogeneity (Hambrick, Cho, \& Chen, 1996). We created a parsimonious composite TMT heterogeneity index by summing three standardized heterogeneity measures: education (Herfindahl-Hirschman index: sciences, business and economics, arts, engineering and law); functional background (HerfindahlHirschman index: production-operations, R\&D and engineering, accounting and finance, management and administration, marketing and sales, law, personnel and labor relations, and others); and firm tenure (the coefficient of variation of members' firm tenure) (Hambrick et al., 1996). Moreover, prior research has shown that tenure diversity is negatively related to team members' perception of psychological safety (Koopmann, Lanaj, Wang, Zhou, \& Shi, 2016), and hence we controlled for TMT tenure diversity (the coefficient of variation of the number of years members had served on TMTs, Cannella, Park, \& Lee, 2008).

We controlled for CEO age as it may confound the relationship between TMT gender diversity and psychological safety. Research indicates that as CEOs' age increases, their attitudes toward diversity become more open (Ng \& Sears, 2012), and leaders' inclusive attitudes have been found to positively associate with team psychological safety (Hirak, Peng, Carmeli, \& Schaubroeck, 2012). In contrast, CEO-TMT power distance may negatively affect TMT psychological safety. Studies have shown that leaders with high power over others not only suppress others' voice-raising (Keltner, Gruenfeld, \& Anderson, 2003) but also inhibit trust building in interactions (De Jong, Van der Vegt, \& Molleman, 2007). We first captured executive power with two widely used indicators - founder status $(1=$ if the executive was a founder of the firm, $0=$ otherwise) and service on other boards (the number of other corporate boards on which the executive serves) (Briscoe, Chin, \& Hambrick, 2014). To calculate CEO-TMT power distance, we used the coefficient of 
variation $^{3}$ of the CEO power and the averaged power of other TMT members for each indicator and summed their standardized values (Haleblian \& Finkelstein, 1993).

Moreover, firm past performance may shape TMT psychological safety. Edmondson (1999) suggested that the lack of tried-and-true solutions resulting from poor past performance creates a rationale for developing team psychological safety that encourages openly discussing past mistakes. We measured firm past performance by the scale from Ling et al. (2008) $(\alpha=.95)$. We further included firm and industry factors that might affect ASO. Large firm size (the number of full-time employees) creates inertia and hampers the firm's flexibility in allocating resources between exploration and exploitation, thus inhibiting ASO (Cao et al., 2010). We also controlled for firm age (in years) to rule out the alternative explanation that younger firms face greater difficulty in managing complex product portfolios to achieve ASO (Fernhaber \& Patel, 2012). Because industries capture environmental influences on firms pursuing ASO, we included the industry sector (dummy variables) of the firms (telecommunications and Internet, computer, environmental and energy, medical and pharmaceuticals, and others) (Lubatkin et al., 2006).

Finally, we followed recommendations for using the lagged dependent variable (LDV) (Bettis, Gambardella, Helfat, \& Mitchell 2014; Harmon, 2019) to reduce potential endogeneity in the relationships related to ASO. We controlled for prior ASO, measured one year earlier (t1) using He and Wong (2004)'s scale. The inclusion of the LDV (prior ASO) allowed us to partial out omitted variable biases caused by unobservable, omitted stable factors that affect both TMT psychological safety (or gender diversity) and ASO. ${ }^{4}$

\footnotetext{
${ }^{3}$ As the coefficient of variation only generates positive values of the absolute power difference between CEOs and other members, we assigned a negative sign to it when the CEO power was lower than the averaged power of other TMT members.

${ }^{4} \mathrm{We}$ considered additional controls such as TMT size and TMT overlapping tenure. However, they appeared to be impotent controls (having correlation $|r|<.10$ with DVs) (Becker et al., 2016). Following
} 


\section{Analysis and Results}

Table 1 displays descriptive statistics and correlations. We used ordinary least squares (OLS) hierarchical regressions to test $\mathrm{H} 1$ and H2. Variance inflation factors (VIFs) (1.12 to 4.38) were all well below the rule-of-thumb cutoff of 10, suggesting that multicollinearity was not a major confound (O’Brien, 2007). We used bootstrapping-based approaches to test mediation (H3) and moderated-mediation (H4) hypotheses.

Models 1 and 4 in Table 2 contain controls only. TMT heterogeneity, commonly regarded as a cognitive-variety proxy, does not predict the interpersonal dynamic of TMT psychological safety. Several other controls significantly relate to the dependent variables (DVs), as expected. CEO age positively, and firm past performance negatively, relate to TMT psychological safety. Firm size and firm age are significant predictors of ASO. Prior ASO is significantly related to both TMT psychological safety and ASO.

Insert Tables 1 and 2 about here

Main effects. As shown in Table 3, TMT gender diversity relates positively to TMT psychological safety (Model 2: $B=.57, p<.01$ ), and TMT psychological safety relates positively to ASO (Model 5: $B=3.88, p<.01$ ). These results support H1 and H2.

Mediation effect of TMT psychological safety. We tested the mediation hypothesis (H3) based on a bias-corrected bootstrapping approach (Preacher \& Hayes, 2008). Bootstrapping overcomes the shortcomings (e.g., the lack of an explicit test of mediation) of the causal steps approach of Baron and Kenny (1986), as well as the low ability to detect effects, high Type I error rate, and reliance on normality assumption by the Sobel test (MacKinnon, Lockwood, 
Hoffman, West, \& Sheets, 2002). Strategy research increasingly uses this approach for mediation testing (e.g., Chen \& Nadkarni, 2017). Exclusion of zero in the bootstrap confidence interval (CI) confirms mediation effects (Hayes, 2013).

Using 10,000 bootstrap samples and 95 percent CIs in the PROCESS macro (Hayes, 2013), we found a significant positive indirect effect of TMT gender diversity on ASO via TMT psychological safety. The estimation of the indirect effect is $2.20(S E=.78, \mathrm{CI}=[.87$, 3.99]), supporting H3. Additionally, the results showed that the direct effect of TMT gender diversity on ASO after partialling out the mediation of TMT psychological safety was insignificant $(B=.72, S E=1.25, \mathrm{CI}=[-1.76,3.21])$. The total effect of TMT gender diversity on ASO, as the sum of direct and indirect effects, was significant $(B=2.93, S E=1.40, \mathrm{CI}=$ $[.14,5.71])$. Overall, these findings indicate that TMT gender diversity does not affect ASO directly, but through the intervening mechanism of TMT psychological safety. This evidence corroborates the key tenet of the upper echelons perspective that TMT diversity shapes firm strategies through intervening TMT processes (Carpenter et al., 2004).

Moderated-mediation effects. In H4, we theorized a "first and second stage moderated mediation" model (Hayes, 2015: 7), where firm slack moderates the indirect effect at both the first (TMT gender diversity $\rightarrow$ TMT psychological safety) and second stage (TMT psychological safety $\rightarrow$ ASO). We began by examining the first-stage and second-stage moderated-mediation models, respectively, based on the index of moderated mediation (Hayes, 2015). Because this index is essentially a product of regression coefficients, Hayes (2015) recommended using bootstrapping to derive its statistical inference. The statistical inference that this index is different from zero serves as "a formal test of moderated mediation," indicating that "any two conditional indirect effects estimated at different values of the moderator are significantly different from each other" (Hayes, 2015: 2). 
First, we examined the first-stage moderated-mediation model by applying Model 7 in the PROCESS macro (Hayes, 2013). The test yielded a significant moderated mediation index $(=-2.00, S E=1.03, \mathrm{CI}=[-4.34,-.31])$. We then estimated the indirect effects of TMT gender diversity on ASO via TMT psychological safety at low $(M-1 S D)$ and high $(M+1 S D)$ levels of firm slack. When slack is low, the indirect effect is significantly positive $(B=3.31$, $S E=1.09, \mathrm{CI}=[1.60,5.97])$, but it is insignificant when slack is high $(B=.13, S E=1.03, \mathrm{CI}$ $=[-1.87,2.24])$. Table $2($ Model 3$)$ shows a negative interaction of TMT gender diversity $\times$ firm slack $(B=-.61, S E=.24, p<.05)$. The simple slope plot (Figure $2 a)$ shows that the effect of TMT gender diversity on psychological safety is significant and positive when firm slack is low $(B=1.01, S E=.26, p<.01)$ but insignificant when slack is high $(B=.04, S E$ $=.28$, n.s.).

Insert Figure $2 \mathrm{a}$ and $2 \mathrm{~b}$ about here

Second, we tested the second-stage moderated-mediation model using Model 14 the PROCESS macro (Hayes, 2013). The indirect effects of TMT gender diversity on ASO via TMT psychological safety vary significantly across different levels of slack (moderated mediation index $=-.84, S E=.47, \mathrm{CI}=[-2.13,-.17])$. The indirect effect is strongly positive when slack is low $(B=2.56, S E=1.08, C I=[.72,5.07])$ and becomes less positive when slack is high $(B=1.21, S E=.60, \mathrm{CI}=[.33,2.86])$. Table 2 (Model 6) reports a significant interaction of TMT psychological safety $\times$ slack $(B=-1.77, S E=.67, p<.01)$. Figure $2 \mathrm{~b}$ shows that the positive effect of TMT psychological safety on ASO is stronger when slack is low $(B=5.33, S E=.82, p<.01)$ than when it is high $(B=2.52, S E=.79, p<.01)$.

Finally, we tested the model in an integrated fashion by applying Model 58 of Hayes 
(2013) to simultaneously test first- and second-stage moderations. ${ }^{5}$ We found that the indirect effect of TMT gender diversity on ASO via TMT psychological safety is significantly positive when slack is low $(B=5.40, S E=1.63, \mathrm{CI}=[2.85,9.35])$ but insignificant when slack is high $(B=.10, S E=.80, \mathrm{CI}=[-1.547,1.86])$. Overall, the results support $\mathrm{H} 4$ that firm slack moderates the indirect effect of TMT gender diversity on ASO via TMT psychological safety, such that this mediated effect is more positive when slack is lower than higher.

\section{Supplemental Analyses}

To strengthen our results, we conducted several supplemental analyses. First, we tested the cognitive-variety explanation associated with TMT gender diversity. Second, we used the commonly adopted TMT female percentage as an alternative gender diversity measure. Third, we tested for potential endogeneity concerns, and fourth, we included alternative controls for robustness checks. Finally, we supplemented key findings with interviews to offer richer insights into the TMT gender diversity phenomenon.

Testing for the cognitive-variety assumption. We measured TMT cognitive variety (t2) as "the variety and amount of information" processed in TMT decision-making by the scale from Dooley and Fryxell (1999: 390) $(\alpha=.78)$. We ran a mediation analysis using TMT psychological safety and cognitive variety as parallel mediators of the TMT gender diversityASO relationship, allowing them to control for each other's mediation effect (Hayes, 2013). TMT psychological safety was still a significant mediator (indirect effect $=1.57, S E=.62, \mathrm{CI}$ $=[.59,3.13])$, whereas the mediation effect of TMT cognitive variety was not significant (indirect effect $=.51, S E=.55, \mathrm{CI}=[-.44,1.77])$. The results suggest that cognitive variety does not serve as an alternative explanation of the effect of TMT gender diversity on ASO.

\footnotetext{
${ }^{5}$ According to Hayes (2015), the moderated-mediation index cannot be directly applied to the first- and second-stage moderated-mediation model, as the indirect effect is a nonlinear function of the moderator.
} 
Alternative measure: TMT female percentage. We reran the models by replacing the measure of TMT gender diversity (Blau's index) with TMT female percentage. TMT female percentage had no linear effect, but it displayed a significant inverted-U relationship (turning point at $48 \%$ ) with TMT psychological safety. The findings strengthened our main results and core contentions that more equal female-male representation in TMTs is better for TMT psychological safety, whereas TMT psychological safety decreases as the gender imbalance increases regardless of a female or male majority. Additionally, we estimated the curvilinear indirect effect of TMT female percentage using the MEDCURVE macro (Hayes \& Preacher, 2010). The results indicate that TMT female percentage has an indirect inverted-U relationship with ASO via TMT psychological safety, which further corroborates our main results (see Appendix II for more detailed procedures and results).

Endogeneity correction. Temporal separations and controlling for the LDV (prior ASO) alleviated endogeneity concerns related to ASO. We further used the instrumental variable 2Stage Least Squares (IV/2SLS) approach to address potential endogeneity in the TMT gender diversity-TMT psychological safety relationship. We employed two IVs measured at t1: the existence of a) prior friendship ties and b) prior colleague ties of women to other TMT member(s) before joining the TMT. Prior friendship or colleague ties increase the chance of women being part of the TMT (Ruef, Aldrich, \& Carter, 2003). However, research has shown that friendship and colleague ties of individual (female) members before the team's inception do not affect the subsequent emergence of team psychological safety, which is an overall team dynamic (Schulte et al., 2012). Following recommended practices (Semadeni, Withers, \& Certo, 2014), we first confirmed the IV strength based on the F statistics $(F=19.69, p$ $<.01$ ) of the IVs from the first stage of 2SLS (Stock, Wright, \& Yogo, 2002). Then, the Sargan test for overidentifying restrictions supported the IV exogeneity $\left(\chi^{2}=.23, p>.05\right)$. 
Finally, the Durbin-Wu-Hausman (DWH) test showed that estimators from OLS and 2SLS did not differ significantly $(F=3.88, p>.05)$. These results indicate that endogeneity did not confound the estimated effect of TMT gender diversity on TMT psychological safety.

Alternative controls. We tested our models using alternative controls, including separate TMT heterogeneity variables (firm tenure, education and functional background; replacing the composite measure); CEO power over the organization (a composite measure of CEO founder status and service on other boards; replacing CEO-TMT power distance); genderweighted TMT tenure diversity (the coefficient of variation of males' averaged TMT tenure and females' averaged TMT tenure within a team; replacing TMT tenure diversity); as well as industry clockspeed (Nadkarni \& Narayanan, 2007) and hypercompetition (Chen, Lin, \& Michel, 2010) (rated by 14 industry experts; $\mathrm{ICC}_{\text {clockspeed }}=.94 ; \mathrm{ICC}_{\text {hypercompetition }}=.87$; replacing industry sectors). Furthermore, we added several additional controls including the TMT variance of psychological safety, TMT size, overlapping tenure, age diversity, CEO education, and location dummies. These additional controls did not alter our main results.

Supplementary interview. To further validate our key quantitative results, we conducted semi-structured interviews of 30-45 minutes each with 23 top managers (11 females and 12 males) of 17 Chinese high-tech SMEs with varied TMT gender diversity. We first probed managers' interpersonal proclivities by asking them, "How do you typically interact with others at work?" Then, to better understand their TMT dynamics, we asked, "How do members in your team typically interact with each other when making strategic decisions?" Based on their responses, we further delved into the interpersonal interactions within their TMTs through follow-up questions.

Table 3 presents key observations from the interviews and representative quotes. We first noted that female executives tended to be more socially sensitive, whereas male executives 
were more inclined to raise voices, supporting the interpersonal gender differences in TMTs. More importantly, we observed that gender-diverse TMTs tended to experience considerable TMT psychological safety; for example, a member of a gender-balanced TMT ( $50 \%$ females) stated: "In our team, no one would be embarrassed to admit mistakes." In contrast, femalemajority TMTs were more prone to seeking cohesion (e.g., a member of a $67 \%$ female TMT said, "We hold back and accept the majority even if we don't agree"), and there seemed to be more conflicts and confrontations in male-majority TMTs (e.g., a member of a 14\% female TMT state.: "There were lots of pushbacks and fights. ... It is very hard for the team to support each other"). Overall, the interviews corroborated our key contentions and conclusions that gender balance is more virtuous for TMT psychological safety than gender imbalance, no matter whether the imbalance is skewed toward a male or female majority.

Insert Table 3 about here

\section{DISCUSSION}

Our results yielded two nuanced insights regarding why and when TMT gender diversity drives ASO. First, TMT gender diversity promoted ASO by fostering the constructive interpersonal TMT dynamic of psychological safety. Second, this interpersonal benefit of TMT gender diversity via psychological safety was amplified when TMTs faced the condition of firm slack scarcity. Next, we discuss the theoretical implications of the results.

\section{Theoretical Implications}

Unique interpersonal strategic advantage of TMT gender diversity. Grounded in the gender-specific, interpersonal differences characterized in social role theory (Eagly \& Wood, 1999), our findings lend credence to the unique interpersonal mechanism (psychological safety) of TMT gender diversity in two ways. First, whereas TMT gender diversity was 
positively related to TMT psychological safety and in turn ASO, other demographic diversity (education, tenure, functional background) was not. Second, the cognitive variety did not mediate the effect of TMT gender diversity on ASO, whereas the positive mediation of TMT psychological safety remained significant after partialling out the mediator of cognitive variety. Consistent with psychological research (Hyde, 2005, 2014; Joel et al., 2015), this evidence suggests that the dominant cognitive-variety perspective does not appear to explain the primary mechanism driven by TMT gender diversity. Thus, our findings challenge the implicit assumption of prior research that TMT gender diversity functions equivalently to other generic demographic proxies of TMT cognitive variety. Instead, its strategic advantage for ASO is uniquely transmitted through TMT psychological safety.

Our study reinforces the need for future TMT research "to treat each demographic diversity variable as a distinct theoretical construct based on the argument that different types of diversity may produce different (process) outcomes" (Pelled, 1996: 618) as well as to directly test these processes. Despite the consensus that TMT diversity (or heterogeneity) is influential within a wide range of firm strategies, including strategic change, diversification, and internationalization (Carpenter et al., 2004), examinations of different forms of TMT diversity have been largely relied on generic theoretical explanations (e.g., cognitive variety). Such a conflated understanding of TMT diversity at best leads to inconclusive findings. At the worst, it causes misattributions of underlying mechanisms, which not only harms the theoretical accuracy but also the prescriptive value of scholarly works. Therefore, we reiterate the call of prior researchers (Carpenter et al., 2004; Pelled, 1996) and urge scholars to pursue future studies that delve into the precise nature of the TMT demographic characteristic diversity and the mechanism in understanding its strategic ramifications. 
Finally, we believe that our findings offer broad implications for strategic orientation research by enriching its micro-foundation. Our study of TMT gender diversity (and the TMT psychological safety mechanism) promotes a better understanding of the emergence of strategic orientation, ASO more specifically, from the upper echelons perspective. Our examination of such micro-mechanisms probes the emergence process-from TMT characteristics to intra-TMT dynamics, and then to firm strategic orientation. Apart from ASO, there could be other strategic orientations, such as entrepreneurial orientation (Lumpkin \& Dess, 1996) and the four proactive strategic orientations (i.e., prospectors, analyzers, differentiated defenders, and low-cost defenders) (Slater et al., 2006), that entail constructive interpersonal dynamics in TMT strategic decision-making. These strategic orientations may well benefit from the TMT psychological safety stemming from gender diversity. We call for further studies that delve into the micro-process of strategic orientation emergence and its interpersonal root in TMT gender diversity.

Balanced versus female-centered approach to TMT gender diversity. Our theorization and findings centered on the complementarity between the interpersonal proclivities of men and women in fostering TMT psychological safety. This more balanced view on both genders departs from the premise of prior studies that the benefits of TMT gender diversity mainly result from women ("the-more-(women)-the-better"). Distinct from the commonly used TMT female percentage measure (e.g., Dezsö \& Ross, 2012; Lyngsie \& Foss, 2017), our operationalization of TMT gender diversity using Blau's index takes both genders into equal account (Harrison \& Klein, 2007; Joshi \& Roh, 2009). Alternatively, we confirmed that TMT female percentage had an inverted-U effect with a turning point close to 50 percent. These results indicate that the gender-balanced approach, compared to the female-centered one, offers a more compelling theoretical account of the strategic benefit of TMT gender diversity. 
We acknowledge that female percentage and gender balance can be operationally equivalent in TMTs with less than 50 percent women. Female proportion in the TMT is generally low $(6.7 \%-24 \%)$ and rarely exceeds 50 percent in large publicly traded U.S. companies (S\&P 1500, Fortune 1000), which were the samples of most prior TMT gender diversity studies (e.g., Dezsö \& Ross, 2012; Krishnan \& Park, 2005). However, this empirical reality has masked the fundamentally distinct theoretical underpinnings of the femalecentered versus the gender balance-based arguments. The former exclusively theorizes the proclivities of women, whereas the latter considers the positive complementarity between men and women. Thus, the female percentage-based approach, due to empirical constraints, may eventually hinder our theoretical understanding of TMT gender diversity.

In contrast, the equal consideration of both men and women is crucial for two reasons. First, gender scholars have stressed that it is pivotal to include men in theorizing gender issues given the integral role of men in facilitating positive gender dynamics in organizations (Fernandez-Mateo \& Kaplan, 2018; Jonson \& Smith, 2018). Our interviews corroborated the crucial role of men in TMTs where women face challenges in strategic decision-making (e.g., excessive consensus seeking). Second, the empirical reality of low female TMT representation is fading in some firm contexts. For example, SMEs in countries such as Colombia, China, and the Caribbean countries increasingly have senior female managers (International Labor Organization [ILO], 2015). Similarly, the significant growth of femaleled start-ups has further boosted the proportion of females in TMTs (Featherstone, 2017). Given this fast-changing landscape of TMT gender composition, the theoretical logic of gender balance becomes increasingly empirically testable in broader firm contexts. The promising results of our study present fruitful opportunities for future researchers to adopt a gender balance-based perspective for understanding TMT gender diversity phenomena. 
Gender diversity theories in team research. Team research has mainly drawn on social categorization and similarity-attraction theories to explain the negative performance impact of gender diversity based on biases, negative attitudes, and stereotypes toward the opposite gender (Joshi \& Roh, 2009). In stark contrast to the "dark side" of gender diversity posited by these team theories, our results highlight its "bright side" and are in line with gender diversity studies of TMTs (Jeong \& Harrison, 2017). This inconsistency may result from the unique TMT context. Compared to relatively short-lived work teams studied in team research, TMT members often interact much more frequently over a longer period (Jackson, Joshi, \& Erhardt, 2003). Studies have shown that as members get to know each other over time, surface-level stereotypes and biases are likely replaced by team interactions derived from members' deep-level proclivities (Harrison, Price, Gavin, \& Florey, 2002; Ling, Wei, Klimoski, Wu, 2015). Thus, the surface-level negative team dynamics, characterized in social categorization and similarity-attraction theories, may not apply to TMTs. Instead, the more deep-level, social-role proclivities are more likely to dominate TMT interactions, underpinning the positive effect of TMT gender diversity on TMT psychological safety.

Our results, juxtaposed with team research, suggest that gender diversity may have both surface- and deep-level implications. Although evidence is sparse, researchers have indicated that the same diversity construct can exhibit both surface- and deep-level functioning (Van Vianen, De Pater, Kristof-Brown, \& Johnson, 2004). However, such complex multi-faceted implications have not been investigated for gender diversity. Social role theory can be a potential theoretical lens for understanding the deep-level functionalities of gender diversity, and it complements the categorization and similarity-attraction paradigm that focuses on its surface-level dysfunctionalities. Researchers are encouraged in future studies to examine the longitudinal unfolding of the surface- to deep-level operations of TMT gender diversity. 


\section{Limitations and Future Directions}

The limitations associated with our study warrant acknowledgment and provide opportunities for future research. First, our examination of SMEs could limit the generalizability of our findings to large and established firms. Investigation of these companies may provide new insights. Second, our focus on the Chinese context could also limit the generalizability to other countries. Examining whether the interpersonal benefit of gender balance varies in other cultural contexts could be an important area of future research. For example, the potency of TMT gender diversity benefits may differ in countries with higher gender egalitarianism (e.g., Finland) compared to China (House, Hanges, Javidan, Dorfman, \& Gupta, 2004). Third, we focused on ASO as a pertinent outcome, but there could be other important strategic outcomes driven by TMT psychological safety stemming from gender diversity, and we encourage more explorations of this topic in future research. Finally, we examined slack resource as a firm-level boundary condition, but research could further investigate how the mediated effect of TMT gender diversity is moderated by other external environmental factors such as munificence, dynamism, or uncertainty.

\section{CONCLUSION}

This study offers a novel, gender-specific theoretical account of the strategic advantage of TMT gender diversity by unraveling the intervening mechanism of TMT psychological safety. This account a) highlights the unique interpersonal benefit of TMT gender diversity, which deviates sharply from the generic cognitive-variety explanation prevalent in prior literature, and b) considers both men and women in a balanced way. We hope that our social role-based interpersonal lens centered on the complementary proclivities of men and women charts a new direction to advance research on TMT gender diversity. 


\section{REFERENCES}

Ali, M., Metz, I., \& Kulik, C. T. 2015. The impact of work-family programs on the relationship between gender diversity and performance. Human Resource Management, 54(4): 553-576.

Amason, A. C. 1996. Distinguishing the effects of functional and dysfunctional conflict on strategic decision making: Resolving a paradox for top management teams. Academy of Management Journal, 39(1): 123-148.

Andriopoulos, C., \& Lewis, M. W. 2009. Exploitation-Exploration tensions and organizational ambidexterity: Managing paradoxes of innovation. Organization Science, 20(4): 696-717.

Apesteguia, J., Azmat, G., \& Iriberri, N. 2012. The impact of gender composition on team performance and decision making: Evidence from the field. Management Science, 58(1): 78-93.

Baker, T., \& Nelson, R. E. 2005. Creating something from nothing: Resource construction through entrepreneurial bricolage. Administrative Science Quarterly, 50(3): 329-366.

Baron, R. M., \& Kenny, D. A. 1986. The moderator-mediator variable distinction in social psychological research: Conceptual, strategic, and statistical considerations. Journal of Personality and Social Psychology, 51(6): 1173-1182.

Baron-Cohen, S., Wheelwright, S., Hill, J., Raste, Y., \& Plumb, I. 2001. The "Reading the Mind in the Eyes" Test revised version: a study with normal adults, and adults with Asperger syndrome or high-functioning autism. The Journal of Child Psychology and Psychiatry and Allied Disciplines, 42(2): 241-251.

Bear, J. B., \& Woolley, A. W. 2011. The role of gender in team collaboration and performance. Interdisciplinary Science Reviews, 36(2): 146-153.

Becker, T. E., Atinc, G., Breaugh, J. A., Carlson, K. D., Edwards, J. R., et al. 2016. Statistical control in correlational studies: 10 essential recommendations for organizational researchers. Journal of Organizational Behavior, 37(2): 157-167.

Berdahl, J. L. 2007. Harassment based on sex: Protecting social status in the context of gender hierarchy. Academy of Management Review, 32(2): 641-658.

Bettis, R., Gambardella, A., Helfat, C., \& Mitchell, W. 2014. Quantitative empirical analysis in strategic management. Strategic Management Journal, 35(7): 949-953.

Birkinshaw, J., \& Gupta, K. 2013. Clarifying the distinctive contribution of ambidexterity to the field of organization studies. Academy of Management Perspectives, 27(4): 287-298.

Blau, P. M. 1977. Inequality and heterogeneity: A primitive theory of social structure, vol. 7. New York: Free Press.

Bliese, P. D. 2000. Within-group agreement, non-independence, and reliability: Implications for data aggregation and analysis. In K. J. Klein \& S. W. J. Kozlowski (Eds.), Multilevel theory, research, and methods in organizations: Foundations, extensions, and new directions: $349-381$. San Francisco: Jossey-Bass.

Brescoll, V. L. 2016. Leading with their hearts? How gender stereotypes of emotion lead to biased 
evaluations of female leaders. The Leadership Quarterly, 27(3): 415-428.

Briscoe, F., Chin, M. K., \& Hambrick, D. C. 2014. CEO ideology as an element of the corporate opportunity structure for social activists. Academy of Management Journal, 57(6): 1786-1809.

Brislin, R. W. 1980. Translation and content analysis of oral and written materials. Methodology, $389-444$.

Bromiley, P., \& Rau, D. 2016. Social, behavioral, and cognitive influences on upper echelons during strategy process: A literature review. Journal of Management, 42(1): 174-202.

Brown, S. P., \& Leigh, T. W. 1996. A new look at psychological climate and its relationship to job involvement, effort, and performance. Journal of Applied Psychology, 81(4): 358-368.

Cannella, A. A., Park, J.-H., \& Lee, H.-U. 2008. Top management team functional background diversity and firm performance: Examining the roles of team member colocation and environmental uncertainty. Academy of Management Journal, 51(4): 768-784.

Cao, Q., Gedajlovic, E., \& Zhang, H. 2009. Unpacking organizational ambidexterity: Dimensions, contingencies, and synergistic effects. Organization Science, 20(4): 781-796.

Cao, Q., Simsek, Z., \& Zhang, H. 2010. Modelling the joint impact of the CEO and the TMT on organizational ambidexterity. Journal of Management Studies, 47(7): 1272-1296.

Carli, L. L. 2001. Gender and social influence. Journal of Social Issues, 57(4): 725-741.

Carlson, K. D., \& Wu, J. 2012. The illusion of statistical control: Control variable practice in management research. Organizational Research Methods, 15(3): 413-435.

Carmeli, A., Tishler, A., \& Edmondson, A. C. 2012. CEO relational leadership and strategic decision quality in top management teams: The role of team trust and learning from failure. Strategic Organization, 10(1): 31-54.

Carpenter, M. A., Geletkanycz, M. A., \& Sanders, W. G. 2004. Upper echelons research revisited: Antecedents, elements, and consequences of top management team composition. Journal of Management, 30(6): 749-778.

Chen, M.-J., Lin, H.-C., \& Michel, J. G. 2010. Navigating in a hypercompetitive environment: The roles of action aggressiveness and TMT integration. Strategic Management Journal, 31(13): $1410-1430$.

Chen, J., \& Nadkarni, S. 2017. It's about Time! CEOs' temporal dispositions, temporal leadership, and corporate entrepreneurship. Administrative Science Quarterly, 62(1): 31-66.

Cohen, J. 2013. Statistical power analysis for the behavioral sciences. New York: Routledge.

Credit Suisse. 2019. The CS gender 3000 in 2019: The changing face of companies. Oct.

Cronin, M. A., Weingart, L. R., \& Todorova, G. 2011. Dynamics in groups: Are we there yet? The Academy of Management Annals, 5(1): 571-612.

De Clercq, D., \& Belausteguigoitia, I. 2017. The usefulness of tenacity in spurring problem-focused voice: The moderating roles of workplace adversity. Journal of Business and Psychology, 32(4): 479-493. 
De Jong, S. B., Van der Vegt, G. S., \& Molleman, E. 2007. The relationships among asymmetry in task dependence, perceived helping behavior, and trust. Journal of Applied Psychology, 92(6): $1625-1637$.

Dess, G. G., \& Robinson, R. B. 1984. Measuring organizational performance in the absence of objective measures: The case of the privately-held firm and conglomerate business unit. Strategic Management Journal, 5(3): 265-273.

Detert, J. R., \& Edmondson, A. C. 2011. Implicit voice theories: Taken-for-granted rules of selfcensorship at work. Academy of Management Journal, 54(3): 461-488.

Dezsö, C. L., \& Ross, D. G. 2012. Does female representation in top management improve firm performance? A panel data investigation. Strategic Management Journal, 33(9): 1072-1089.

Dooley, R. S., \& Fryxell, G. E. (1999). Attaining decision quality and commitment from dissent: The moderating effects of loyalty and competence in strategic decision-making teams. Academy of Management Journal, 42(4): 389-402.

Eagly, A. H. 1987. Sex differences in social behavior: A social-role interpretation. Hillsdale, NJ: Erlbaum.

Eagly, A. H. 2018. The shaping of science by ideology: How feminism inspired, led, and constrained scientific understanding of sex and gender. Journal of Social Issues, 74(4): 871-888.

Eagly, A. H., Johannesen-Schmidt, M. C., \& Van Engen, M. L. 2003. Transformational, transactional, and laissez-faire leadership styles: a meta-analysis comparing women and men. Psychological Bulletin, 129(4): 569-591.

Eagly, A. H., \& Karau, S. J. 2002. Role congruity theory of prejudice toward female leaders. Psychological Review, 109(3): 573-598.

Eagly, A. H., \& Wood, W. 1999. The origins of sex differences in human behavior: Evolved dispositions versus social roles. American Psychologist, 54(6): 408-423.

Edmondson, A. 1999. Psychological safety and learning behavior in work teams. Administrative Science Quarterly, 44(2): 350-383.

Edmondson, A. C. 2002. The local and variegated nature of learning in organizations: A group-level perspective. Organization Science, 13(2): 128-146.

Edmondson, A. C. 2003. Speaking up in the operating room: How team leaders promote learning in interdisciplinary action teams. Journal of Management Studies, 40(6): 1419-1452.

Edmondson, A. C., \& Lei, Z. 2014. Psychological safety: The history, renaissance, and future of an interpersonal construct. Annual Review of Organizational Psychology and Organizational Behavior, 1(1): 23-43.

Ely, R. J. 1995. The power in demography: Women's social constructions of gender identity at work. Academy of Management Journal, 38(3): 589-634.

Eriksen, W., \& Einarsen, S. 2004. Gender minority as a risk factor of exposure to bullying at work: The case of male assistant nurses. European Journal of Work and Organizational Psychology, 
13(4): 473-492.

Featherstone, E. 2017. The women-led startups smashing the glass ceiling. The Guardian. https://www.theguardian.com/small-business-network/2017/jan/11/women-led-startupssmashing-glass-ceiling-investment. Jan 11.

Fernhaber, S. A., \& Patel, P. C. 2012. How do young firms manage product portfolio complexity? The role of absorptive capacity and ambidexterity. Strategic Management Journal, 33(13): $1516-1539$.

Fernandez-Mateo, I., \& Kaplan, S. 2018. Gender and organization science: Introduction to a virtual special issue. Organization Science, 29(6): 1229-1236.

Finkelstein, S., Hambrick, D. C., \& Cannella, A. A. 2009. Strategic leadership: Theory and research on executives, top management teams, and boards. USA: Oxford University Press.

George, G. 2005. Slack resources and the performance of privately held firms. Academy of Management Journal, 48(4): 661-676.

Ghoshal, S., \& Bartlett, C. A. 1997. The individualized corporation: Great companies are defined by purpose, process and people. New York: HarperPerennial.

Gibson, C. B., \& Birkinshaw, J. 2004. The antecedents, consequences, and mediating role of organizational ambidexterity. Academy of Management Journal, 47(2): 209-226.

Gong, Y., Cheung, S.-Y., Wang, M., \& Huang, J.-C. 2012. Unfolding the proactive process for creativity: Integration of the employee proactivity, information exchange, and psychological safety perspectives. Journal of Management, 38(5): 1611-1633.

Grant Thornton. 2013. Women in senior management: setting the stage for growth. Oct 1.

Grant Thornton. 2017. Women in business: New perspectives on risk and reward. Mar 8.

Haleblian, J., \& Finkelstein, S. 1993. Top management team size, CEO dominance, and firm performance: The moderating roles of environmental turbulence and discretion. Academy of Management Journal, 36(4): 844-863.

Haleblian, J., McNamara, G., Kolev, K., \& Dykes, B. J. 2012. Exploring firm characteristics that differentiate leaders from followers in industry merger waves: A competitive dynamics perspective. Strategic Management Journal, 33(9): 1037-1052.

Hambrick, D. C. 2007. Upper echelons theory: An update. Academy of Management Review, 32(2): 334-343.

Hambrick, D. C., Cho, T. S., \& Chen, M.-J. 1996. The influence of top management team heterogeneity on firms' competitive moves. Administrative Science Quarterly, 659-684.

Harmon, D. J. 2019. When the fed speaks: Arguments, emotions, and the microfoundations of institutions. Administrative Science Quarterly, 64(3): 542-575.

Harrison, D. A., \& Klein, K. J. 2007. What's the difference? Diversity constructs as separation, variety, or disparity in organizations. Academy of Management Review, 32(4): 1199-1228.

Harrison, D. A., Price, K. H., Gavin, J. H., \& Florey, A. T. 2002. Time, teams, and task performance: 
Changing effects of surface-and deep-level diversity on group functioning. Academy of Management Journal, 45(5): 1029-1045.

Hayes, A. F. 2013. Introduction to mediation, moderation, and conditional process analysis. $A$ regression-based approach. New York: The Guildford Press.

Hayes, A. F. 2015. An index and test of linear moderated mediation. Multivariate Behavioral Research, 50(1): 1-22.

Hayes, A. F., \& Preacher, K. J. 2010. Quantifying and testing indirect effects in simple mediation models when the constituent paths are nonlinear. Multivariate Behavioral Research, 45(4): 627660 .

He, Z.-L., \& Wong, P.-K. 2004. Exploration vs. exploitation: An empirical test of the ambidexterity hypothesis. Organization Science, 15(4): 481-494.

Heavey, C., \& Simsek, Z. 2017. Distributed cognition in top management teams and organizational ambidexterity: The influence of transactive memory systems. Journal of Management, 43(3): 919-945.

Heilman, M. E., \& Okimoto, T. G. 2007. Why are women penalized for success at male tasks?: The implied communality deficit. Journal of Applied Psychology, 92(1): 81-92.

Hirak, R., Peng, A. C., Carmeli, A., \& Schaubroeck, J. M. 2012. Linking leader inclusiveness to work unit performance: The importance of psychological safety and learning from failures. The Leadership Quarterly, 23(1): 107-117.

Hoobler, J. M., Masterson, C. R., Nkomo, S. M., \& Michel, E. J. 2018. The business case for women leaders: Meta-analysis, research critique, and path forward. Journal of Management, 44(6): 2473-2499.

House, R. J., Hanges, P. J., Javidan, M., Dorfman, P. W., \& Gupta, V. (Eds.). 2004. Culture, leadership, and organizations: The GLOBE study of 62 societies. London: Sage publications. Hyde, J. S. 2005. The gender similarities hypothesis. American Psychologist, 60(6): 581-592. Hyde, J. S. 2014. Gender similarities and differences. Annual Review of Psychology, 65: 373-398. International Labor Organization. 2015. Global Report: Women in Business and Management. Jan. Jackson, S. E., Joshi, A., \& Erhardt, N. L. 2003. Recent research on team and organizational diversity: SWOT analysis and implications. Journal of Management, 29(6): 801-830.

Jansen, J. J., George, G., Van den Bosch, F. A., \& Volberda, H. W. 2008. Senior team attributes and organizational ambidexterity: The moderating role of transformational leadership. Journal of Management Studies, 45(5): 982-1007.

Jansen, J. J., Simsek, Z., \& Cao, Q. 2012. Ambidexterity and performance in multiunit contexts: Cross-level moderating effects of structural and resource attributes. Strategic Management Journal, 33(11): 1286-1303.

Jansen, J. J., Tempelaar, M. P., Van den Bosch, F. A., \& Volberda, H. W. 2009. Structural differentiation and ambidexterity: The mediating role of integration mechanisms. Organization 
Science, 20(4): 797-811.

Jeong, S.-H., \& Harrison, D. A. 2017. Glass breaking, strategy making, and value creating: Metaanalytic outcomes of women as CEOs and TMT members. Academy of Management Journal, 60(4): 1219-1252.

Joel, D., Berman, Z., Tavor, I., Wexler, N., Gaber, O., Stein, Y., et al. 2015. Sex beyond the genitalia: The human brain mosaic. Proceedings of the National Academy of Sciences, 112(50): 1546815473.

Jonson, W. B., \& Smith, D. G. 2018. How men can become better allies to women. Harvard Business Review. https://hbr.org/2018/10/how-men-can-become-better-allies-to-women. Oct 12.

Joshi, A., \& Roh, H. 2009. The role of context in work team diversity research: A meta-analytic review. Academy of Management Journal, 52(3): 599-627.

Kahn, W. A. 1990. Psychological conditions of personal engagement and disengagement at work. Academy of Management Journal, 33(4): 692-724.

Kanter, R. M. 1977. Men and women of the corporation. New York: Basic Books.

Keltner, D., Gruenfeld, D. H., \& Anderson, C. 2003. Power, approach, and inhibition. Psychological Review, 110(2): 265-284.

Koopmann, J., Lanaj, K., Wang, M., Zhou, L., \& Shi, J. 2016. Nonlinear effects of team tenure on team psychological safety climate and climate strength: Implications for average team member performance. Journal of Applied Psychology, 101(7): 940-957.

Kostopoulos, K. C., \& Bozionelos, N. 2011. Team exploratory and exploitative learning: Psychological safety, task conflict, and team performance. Group \& Organization Management, 36(3): 385-415.

Krishnan, H. A., \& Park, D. 2005. A few good women—on top management teams. Journal of Business Research, 58(12): 1712-1720.

LeBreton, J. M., \& Senter, J. L. 2008. Answers to 20 questions about interrater reliability and interrater agreement. Organizational Research Methods, 11(4): 815-852.

Lee, H. W., Choi, J. N., \& Kim, S. 2018. Does gender diversity help teams constructively manage status conflict? An evolutionary perspective of status conflict, team psychological safety, and team creativity. Organizational Behavior and Human Decision Processes, (144): 187-199.

LePine, J. A., Hollenbeck, J. R., Ilgen, D. R., Colquitt, J. A., \& Ellis, A. 2002. Gender composition, situational strength, and team decision-making accuracy: A criterion decomposition approach. Organizational Behavior and Human Decision Processes, 88(1): 445-475.

LePine, J. A., \& Van Dyne, L. 1998. Predicting voice-behavior tendency in work groups. Journal of Applied Psychology, 83(6): 853-868.

LePine, J. A., \& Van Dyne, L. 2001. Voice and cooperative behavior as contrasting forms of contextual performance: evidence of differential relationships with big five personality characteristics and cognitive ability. Journal of Applied Psychology, 86(2): 326-336. 
Ling, Y. A. N., Simsek, Z., Lubatkin, M. H., \& Veiga, J. F. 2008. Transformational leadership's role in promoting corporate entrepreneurship: Examining the CEO-TMT interface. Academy of Management Journal, 51(3): 557-576.

Ling, Y., Wei, L. Q., Klimoski, R., \& Wu, L. 2015. Benefiting from CEOs' empowerment of TMTs: Does CEO-TMT dissimilarity matter. Leadership Quarterly, 26(6): 1066-1079.

Lubatkin, M. H., Simsek, Z., Ling, Y., \& Veiga, J. F. 2006. Ambidexterity and performance in small-to medium-sized firms: The pivotal role of top management team behavioral integration. Journal of Management, 32(5): 646-672.

Lumpkin, G. T., \& Dess, G. G. 1996. Clarifying the entrepreneurial orientation construct and linking it to performance. Academy of management Review, 21(1): 135-172.

Lyngsie, J., \& Foss, N. J. 2017. The more, the merrier? Women in top-management teams and entrepreneurship in established firms. Strategic Management Journal, 38(3): 487-505.

MacKinnon, D. P., Lockwood, C. M., Hoffman, J. M., West, S. G., \& Sheets, V. 2002. A comparison of methods to test mediation and other intervening variable effects. Psychological Methods, 7(1): $83-104$.

March, J. G. 1991. Exploration and exploitation in organizational learning. Organization Science, 2(1): 71-87.

McKinsey \& Company. 2015. Why diversity matters. https://www.mckinsey.com/businessfunctions/organization/our-insights/why-diversity-matter. Jan.

McKinsey \& Company. 2018. Delivering through diversity. https://www.mckinsey.com/businessfunctions/organization/our-insights/delivering-through-diversity. Jan.

Mihalache, O. R., Jansen, J. J., Van den Bosch, F. A., \& Volberda, H. W. 2014. Top management team shared leadership and organizational ambidexterity: A moderated mediation framework. Strategic Entrepreneurship Journal, 8(2): 128-148.

Moskowitz, D. S., Suh, E. J., \& Desaulniers, J. 1994. Situational influences on gender differences in agency and communion. Journal of Personality and Social Psychology, 66(4): 753-761.

Moss-Racusin, C. A., Phelan, J. E., \& Rudman, L. A. 2010. When men break the gender rules: Status incongruity and backlash against modest men. Psychology of Men \& Masculinity, 11(2): 140151.

Nadkarni, S., \& Herrmann, P. O. L. 2010. CEO personality, strategic flexibility, and firm performance: The case of the Indian business process outsourcing industry. Academy of Management Journal, 53(5): 1050-1073.

Nadkarni, S., \& Narayanan, V. K. 2007. Strategic schemas, strategic flexibility, and firm performance: The moderating role of industry clockspeed. Strategic Management Journal, 28(3): 243-270.

Nembhard, I. M., \& Edmondson, A. C. 2006. Making it safe: The effects of leader inclusiveness and professional status on psychological safety and improvement efforts in health care teams. 
Journal of Organizational Behavior, 27(7): 941-966.

Ng, E. S., \& Sears, G. J. 2012. CEO leadership styles and the implementation of organizational diversity practices: Moderating effects of social values and age. Journal of Business Ethics, 105(1): 41-52.

Oakley, A. 2000. Experiments in knowing: Gender and method in the social sciences. Cambridge: Polity Press.

O'Brien, R. M. 2007. A caution regarding rules of thumb for variance inflation factors. Quality $\boldsymbol{\&}$ Quantity, 41(5): 673-690.

Orr, E. \& Stevenson, J. 2017. What makes women CEOs different? Korn Ferry Institute Reports \& Insights. https://www.kornferry.com/institute/women-ceo-insights. Nov 08.

Ou, A. Y., Waldman, D. A., \& Peterson, S. J. 2018. Do humble CEOs matter? An examination of CEO humility and firm outcomes. Journal of Management, 44(3): 1147-1173.

Pelled, L. H. 1996. Demographic diversity, conflict, and work group outcomes: An intervening process theory. Organization Science, 7(6): 615-631.

Podsakoff, P. M., MacKenzie, S. B., Lee, J.-Y., \& Podsakoff, N. P. 2003. Common method biases in behavioral research: a critical review of the literature and recommended remedies. Journal of Applied Psychology, 88(5): 879-903.

Post, C. 2015. When is female leadership an advantage? Coordination requirements, team cohesion, and team interaction norms. Journal of Organizational Behavior, 36(8): 1153-1175.

Post, C., Latu, I. M., \& Belkin, L. Y. 2019. A female leadership trust advantage in times of crisis: Under what conditions? Psychology of Women Quarterly, 43(2): 215-231.

Preacher, K. J., \& Hayes, A. F. 2008. Asymptotic and resampling strategies for assessing and comparing indirect effects in multiple mediator models. Behavior Research Methods, 40(3): 879-891.

Qian, C., Cao, Q., \& Takeuchi, R. 2013. Top management team functional diversity and organizational innovation in China: The moderating effects of environment. Strategic Management Journal, 34(1): 110-120.

Rudman, L. A., \& Glick, P. 1999. Feminized management and backlash toward agentic women: The hidden costs to women of a kinder, gentler image of middle managers. Journal of Personality and Social Psychology, 77(5): 1004-1010.

Rudman, L. A., \& Mescher, K. 2013. Penalizing men who request a family leave: Is flexibility stigma a femininity stigma? Journal of Social Issues, 69(2): 322-340.

Ruef, M., Aldrich, H. E., \& Carter, N. M. 2003. The structure of founding teams: Homophily, strong ties, and isolation among US entrepreneurs. American Sociological Review, 68(2): 195-222.

Sawdye, C. 2017. Inside the mind of the male and female CEO: should we mind the gap? The CEO agenda. PwC Global. https://www.pwc.com/gx/en/ceo-agenda/pwc-at-davos/blogs/ 2017/insidethe-mind-of-the-male-and-female-ceo-should-we-mind-the-gap.html. Dec 27. 
Schulte, M., Cohen, N. A., \& Klein, K. J. 2012. The coevolution of network ties and perceptions of team psychological safety. Organization Science, 23(2): 564-581.

Semadeni, M., Withers, M. C., \& Certo, S. T. 2014. The perils of endogeneity and instrumental variables in strategy research: Understanding through simulations. Strategic Management Journal, 35(7): 1070-1079.

Simsek, Z., Veiga, J. F., \& Lubatkin, M. H. 2007. The impact of managerial environmental perceptions on corporate entrepreneurship: Towards understanding discretionary slack's pivotal role. Journal of Management Studies, 44(8): 1398-1424.

Simsek, Z., Veiga, J. F., Lubatkin, M. H., \& Dino, R. N. 2005. Modeling the multilevel determinants of top management team behavioral integration. Academy of Management Journal, 48(1): 6984.

Slater, S. F., Olson, E. M., \& Hult, G. T. M. 2006. The moderating influence of strategic orientation on the strategy formation capability-performance relationship. Strategic Management Journal, 27(12): 1221-1231.

Smith, K. G., Smith, K. A., Olian, J. D., Sims Jr, H. P., O’Bannon, D. P., et al. 1994. Top management team demography and process: The role of social integration and communication. Administrative Science Quarterly, 412-438.

Smith, W. K., \& Tushman, M. L. 2005. Managing strategic contradictions: A top management model for managing innovation streams. Organization Science, 16(5): 522-536.

Stock, J. H., Wright, J. H., \& Yogo, M. 2002. A survey of weak instruments and weak identification in generalized method of moments. Journal of Business \& Economic Statistics, 20(4): 518-529.

Torchia, M., Calabrò, A., \& Huse, M. 2011. Women directors on corporate boards: From tokenism to critical mass. Journal of Business Ethics, 102(2): 299-317.

Tucker, A. L., \& Edmondson, A. C. 2003. Why hospitals don't learn from failures: Organizational and psychological dynamics that inhibit system change. California Management Review, 45(2): $55-72$.

Turturea, R., Jansen, J., \& Verheul, I. 2015. TMT improvisation, resource management and SME performance: A mediated model. Frontiers of Entrepreneurship Research, 35(9): 218-223.

Tushman, M. L., \& Nadler, D. A. 1978. Information processing as an integrating concept in organizational design. Academy of Management Review, 3(3): 613-624.

Van Dyne, L., \& LePine, J. A. 1998. Helping and voice extra-role behaviors: Evidence of construct and predictive validity. Academy of Management Journal, 41(1): 108-119.

Van Vianen, A. E. M., De Pater, I. E., Kristof-Brown, A. L., \& Johnson, E. C. 2004. Fitting in: Surface- and deep-level cultural differences and expatriates' adjustment. Academy of Management Journal, 47(5): 697-709.

Wall, T. D., Michie, J., Patterson, M., Wood, S. J., Sheehan, M., et al. 2004. On the validity of subjective measures of company performance. Personnel Psychology, 57(1): 95-118. 
Wegge, J., Roth, C., Neubach, B., Schmidt, K.-H., \& Kanfer, R. 2008. Age and gender diversity as determinants of performance and health in a public organization: The role of task complexity and group size. Journal of Applied Psychology, 93(6): 1301-1313.

Weiss, M., Hoegl, M., \& Gibbert, M. 2011. Making virtue of necessity: The role of team climate for innovation in resource-constrained innovation projects. Journal of Product Innovation Management, 28(s1): 196-207.

Wilhelm, H., Richter, A. W., \& Semrau, T. 2019. Employee learning from failure: A team-as-resource perspective. Organization Science, 30(4): 694-714.

Williams, M., \& Polman, E. 2015. Is it me or her? How gender composition evokes interpersonally sensitive behavior on collaborative cross-boundary projects. Organization Science, 26(2): 334355.

Witt, M. G., \& Wood, W. 2010. Self-regulation of gendered behavior in everyday life. Sex Roles, 62(9-10): 635-646.

Wood, W. 1987. Meta-analytic review of sex differences in group performance. Psychological Bulletin, 102(1): 53-71.

Wood, W., Christensen, P. N., Hebl, M. R., \& Rothgerber, H. 1997. Conformity to sex-typed norms, affect, and the self-concept. Journal of Personality and Social Psychology, 73(3): 523-535.

Wood, W., \& Eagly, A. H. 2002. A cross-cultural analysis of the behavior of women and men: Implications for the origins of sex differences. Psychological Bulletin, 128(5): 699-727.

Woolley, A. W., Chabris, C. F., Pentland, A., Hashmi, N., \& Malone, T. W. 2010. Evidence for a collective intelligence factor in the performance of human groups. Science, 330(6004): 686-688.

Zahra, S. A., Ireland, R. D., \& Hitt, M. A. 2000. International expansion by new venture firms: International diversity, mode of market entry, technological learning, and performance. Academy of Management Journal, 43(5): 925-950.

Zhu, L.-Q. 2017. Top 10 Chinese cities for entrepreneurship and innovation in 2017. http://www.chinadaily.com.cn/business/2017top10/2017-09/21/content_32275807_9.htm. 
Table 1. Descriptive Statistics and Correlations among Study Variables

\begin{tabular}{|c|c|c|c|c|c|c|c|c|c|c|c|c|c|}
\hline & Mean & $S D$ & 1. & 2. & 3. & 4. & 5. & 6. & 7. & 8. & 9. & 10. & 11. \\
\hline 1. TMT heterogeneity & .00 & 1.66 & & & & & & & & & & & \\
\hline 2. TMT tenure diversity & .08 & .15 & $.19^{*}$ & & & & & & & & & & \\
\hline 3. CEO age & 40.34 & 6.02 & -.04 & .01 & & & & & & & & & \\
\hline 4. CEO-TMT power distance & .00 & 1.28 & .15 & .08 & .04 & & & & & & & & \\
\hline 5. Firm past performance & 4.73 & .87 & .11 & .15 & .14 & .11 & & & & & & & \\
\hline 6. Firm size & 58.88 & 66.17 & .03 & .08 & .001 & -.03 & $.22 * *$ & & & & & & \\
\hline 7. Firm age & 12.22 & 1.88 & $.24^{* *}$ & .13 & $.32 * *$ & .06 & $.18^{*}$ & $.28 * *$ & & . & & & \\
\hline 8. Prior $\mathrm{ASO}^{\mathrm{a}}$ & 16.92 & 3.32 & -.03 & $.18 \dagger$ & .13 & -.03 & $.26^{* *}$ & $.23 *$ & $.16 \dagger$ & & & & \\
\hline 9. TMT gender diversity & .31 & .21 & -.08 & -.02 & .12 & .001 & $.18^{*}$ & .12 & .15 & .12 & & & \\
\hline 10. Firm slack & 4.43 & .79 & $.17 \dagger$ & .03 & -.06 & .14 & $.27^{* *}$ & .04 & .01 & -.07 & .14 & & \\
\hline 11. TMT psychological safety & 4.51 & .47 & -.10 & .06 & $.25^{* *}$ & -.14 & -.15 & -.02 & .12 & $.25^{* *}$ & $.21 *$ & $-.37^{* *}$ & \\
\hline 12. $\mathrm{ASO}^{\mathrm{a}}$ & 16.23 & 3.50 & -.06 & $.17 \dagger$ & $.31^{* *}$ & .03 & .14 & -.01 & $.25^{* *}$ & $.42 * *$ & $.26^{* *}$ & .07 & $.53^{* *}$ \\
\hline $\mathrm{n}=120$ & $\dagger p<.10(\mathrm{t}$ & -tailed) & $* p<.0$ & two-tail & $; * * p<$ & $01(\mathrm{tw}$ & led); * & $p<.00$ & wo-taile & & & & \\
\hline
\end{tabular}


Table 2. Results of OLS Regression Analyses of TMT Psychological Safety and ASO ${ }^{\text {a }}$

\begin{tabular}{|c|c|c|c|c|c|c|c|c|c|c|c|c|}
\hline \multirow[b]{3}{*}{ Controls } & \multicolumn{6}{|c|}{ TMT Psychological Safety } & \multicolumn{6}{|c|}{$\mathbf{A S O}^{\mathbf{a}}$} \\
\hline & \multicolumn{2}{|c|}{$\underline{\text { Model } 1}$} & \multicolumn{2}{|c|}{$\underline{\text { Model } 2}$} & \multicolumn{2}{|c|}{$\underline{\text { Model } 3}$} & \multicolumn{2}{|c|}{$\underline{\text { Model } 4}$} & \multicolumn{2}{|c|}{$\underline{\text { Model } 5}$} & \multicolumn{2}{|c|}{$\underline{\text { Model } 6}$} \\
\hline & $\boldsymbol{B}$ & $S E$ & $\boldsymbol{B}$ & $S E$ & $\boldsymbol{B}$ & $S E$ & $\boldsymbol{B}$ & $S E$ & $\boldsymbol{B}$ & $S E$ & $\boldsymbol{B}$ & $S E$ \\
\hline TMT heterogeneity & -.02 & .03 & -.001 & .02 & -.01 & .02 & -.17 & .19 & -.15 & .16 & -.11 & .15 \\
\hline TMT tenure diversity & -.003 & .30 & .14 & .29 & .13 & .28 & 3.04 & 2.17 & 2.53 & 1.82 & 2.80 & 1.78 \\
\hline CEO age & $.02 * *$ & .01 & $.02 *$ & .01 & $.02 *$ & .01 & $.13 *$ & .05 & .07 & .04 & $.07 \dagger$ & .04 \\
\hline CEO-TMT power distance & -.03 & .03 & -.02 & .03 & -.03 & .03 & -.02 & .23 & .05 & .19 & .09 & .19 \\
\hline Firm past performance & $-.12 *$ & .05 & $-.10 \dagger$ & .05 & $-.11 *$ & .05 & .12 & .35 & .24 & .31 & .45 & .31 \\
\hline Firm size $(\log )$ & -.03 & .05 & -.03 & .05 & -.02 & .05 & $-.95 *$ & .39 & $-.84 *$ & .32 & $-.94 * *$ & .31 \\
\hline Firm age & .03 & .03 & .02 & .02 & .01 & .02 & $.38 *$ & .18 & $.31 \dagger$ & .16 & .21 & .16 \\
\hline Prior $\mathrm{ASO}^{\mathrm{a}}$ & $.03 *$ & .01 & $.03 *$ & .01 & $.03 * *$ & .01 & $.41 * * *$ & .09 & $.29 * * *$ & .08 & $.26 * *$ & .08 \\
\hline Industry sector & YES & & YES & & YES & & YES & & YES & & YES & \\
\hline \multicolumn{13}{|l|}{ Main effects } \\
\hline TMT gender diversity & & & $.57 * *$ & .19 & $3.23 * *$ & 1.08 & & & .72 & 1.25 & .15 & 1.24 \\
\hline Firm slack & & & $-.17 * *$ & .05 & .03 & .09 & & & $1.22 * *$ & .35 & $11.76^{* * *}$ & 3.05 \\
\hline TMT psychological safety & & & & & & & & & $3.88 * * *$ & .62 & $9.52 * *$ & 3.17 \\
\hline \multicolumn{13}{|l|}{ Interactions } \\
\hline $\begin{array}{l}\text { TMT gender diversity } \\
\times \text { Firm slack }\end{array}$ & & & & & $-.61 *$ & .24 & & & & & & \\
\hline $\begin{array}{l}\text { TMT psychological safety } \\
\times \text { Firm slack }\end{array}$ & & & & & & & & & & & $-1.77 * *$ & .67 \\
\hline $\mathrm{F}$ & $2.90 * *$ & & $3.97 * * *$ & & $4.31 * * *$ & & $4.15 * * *$ & & $8.08 * * *$ & & $8.44 * * *$ & \\
\hline Adjusted $\mathrm{R}^{2}$ & .16 & & .26 & & .29 & & .24 & & .47 & & .50 & \\
\hline $\mathrm{n}=120$ & $p<.10$ & & $p<.05$ & two-t & $* * p<.01$ & (two- & $* * p<.001$ & (two & & & & \\
\hline
\end{tabular}

a. ASO: ambidextrous strategic orientation 
Social-role Based Interpersonal Proclivities of Female and Male Top Managers

\begin{tabular}{|c|c|}
\hline \multirow{6}{*}{$\begin{array}{l}\text { Observations } \\
\text { Female top } \\
\text { managers are } \\
\text { more socially } \\
\text { sensitive }\end{array}$} & Interpersonal proclivities of female top managers \\
\hline & Representative quotes \\
\hline & "I often take others' needs into consideration and \\
\hline & carefully respond to their concerns. ... When I propose a \\
\hline & project, I think in other members' shoes, like what they \\
\hline & would care about or how they could benefit from the \\
\hline & $\begin{array}{l}\text { project. ... This helps me better communicate with each } \\
\text { member." - Female CEO, Electronics firm. }\end{array}$ \\
\hline & "In our company, we say hi to each other every \\
\hline & morning. . . I can tell when someone sounds upset. And \\
\hline & I'll talk to the person to see if he/she is having trouble at \\
\hline & $\begin{array}{l}\text { work or even in life." - Female CEO, Nuclear technology } \\
\text { firm. }\end{array}$ \\
\hline & "I can quickly sense any tension in our team before it gets \\
\hline & heated.... I try to personally speak to everyone and to \\
\hline & remove any misunderstandings among them. This often \\
\hline & $\begin{array}{l}\text { calms them down and eases the tension."- Female COO, } \\
\text { Materials firm. }\end{array}$ \\
\hline
\end{tabular}

\section{Observations \\ Male top}

managers have a

higher voice-

raising tendency

\section{Interpersonal proclivities of male top managers}

\section{Representative quotes}

"As the head (of the department), it is my job to go all the way to fight for resources. ... I often see men fighting harder in my team as well. ... I never hesitate to be the first to speak up, I don't hold back even if no one else raises voice." - Male COO, Internet firm.

"Men are usually the first to speak up their opinions. ... I was once excited about developing a collaboration project with another company. ... Everyone seemed to agree with me until a (male) member jumped out and said he did not think it was a good idea. Then only after that, all the others started to express their concerns about this collaboration. . .." - Male CEO, IT firm.

"I'm very direct in communicating my views. . . . I wouldn't hesitate to point out someone's problem. ... I really think that as a top manager, we have to face the problems directly, instead of holding back just not to hurt feelings" - Male head of Engineering, Medical devices firm.

TMT Gender Diversity and Psychological Safety

\begin{tabular}{|c|c|c|c|}
\hline & TMTs with higher gender diversity & & TMTs with lower gender diversity \\
\hline Observations & Representative quotes & Observations & Representative quotes \\
\hline $\begin{array}{l}\text { More gender- } \\
\text { diverse TMTs } \\
\text { have higher } \\
\text { psychological } \\
\text { safety }\end{array}$ & $\begin{array}{l}\text { "One year after I joined the company, I suggested to } \\
\text { restructure our promotion system. . . . There were a lot of } \\
\text { tough questions when I first proposed it, but they didn't } \\
\text { mean to put me down. . . . Members expressed their } \\
\text { genuine concerns but were very respectful. I never felt as } \\
\text { if my team was judging me as a newcomer who just }\end{array}$ & $\begin{array}{l}\text { Female-majority } \\
\text { TMTs have } \\
\text { lower } \\
\text { psychological } \\
\text { safety and more } \\
\text { cohesion-seeking }\end{array}$ & $\begin{array}{l}\text { "We try hard to keep good relationships with each other and } \\
\text { don't' want to break the peace. . . Normally, we hold back and } \\
\text { accept the majority even if we don't agree. . . In this way, we } \\
\text { avoid direct confrontations, which are very embarrassing." - } \\
\text { Female COO, Environment technology firm ( } 67 \% \text { females in } \\
\text { TMT). }\end{array}$ \\
\hline
\end{tabular}


wanted to 'change the game'.... They trusted me once I convinced them that it was the best thing for our company. ..." - Female head of HR, Electronics firm (43\% females in TMT).

"In our team, we don't feel embarrassed to admit mistakes. We all understand that no one is perfect. ... once insisted on investing in a new technological company as I thought their technology was promising and could be useful to us. But it turned out that it was not a wise investment. ... I apologized to the members who were initially against this decision, and they were understanding and willing to share the responsibility as a team." - Female CEO, Nuclear technology firm (50\% females in TMT)

"We are open to each other's criticism. . . . There is not much hierarchical power going on within the team. We can directly challenge an idea even it's from the CEO... For example, he (the CEO) was proposing that we should do safety checks every two weeks rather than monthly. Our operation director directly questioned it: 'this is unrealistic and would be a waste of our resources.' The CEO soon acknowledged that he was indeed too ambitious. ... Communications among us are very open. ... when there is a problem, we sit together to find a solution. If we can't, then we set up another meeting and talk further, in front of each other but never behind each other's back." - Male CTO, Chemical firm (43\% females in TMT)
"In the team, when we noticed others' mistake, we never openly call it out. Or sometimes we pretend not knowing it. . . . Because we fear that it will make people 'lose face,' so we just drop hints and hope that the person would get it" - Female CEO, Materials firm $(67 \%$ females in TMT).
Male-majority TMTs have

lower

psychological

safety and more conflicts
"There have been many fights in our team. Recently, between the head of finance and the head of sales. ... The finance manager was sceptical about the budget plan from the sales manager and insulted him as being incompetent. . . This really offended the sales manager, and he accused the finance manager being ignorant who has not right to interfere their (the sales') business. . . . They even threatened to leave the company if the other stay. ..." - Male CEO, IT firm (20\% females in TMT).

"Two years ago, one of the members wanted to initiate a major strategic transition in our company. He had private conversations separately with each of us. Only after he was sure that everyone would agree, he raised it in our group meeting. . . . Because when someone proposes a big decision like that, directly in front of the group members, there will be lots of pushbacks and fights. ..." Male HR head, Biomedical firm (14\% females in TMT).

"Men in our team are generally very competitive and have a strong desire to conquer. ... when we (males) receive critiques, we take it personally and feel agitated. . . . So we attack back. . . The atmosphere of my current (all-male) team is much worse than the (mix-gender) team I worked in before. . . . Our conflicts are more intense. No one wants to be the 'loser' and admit they are wrong or inferior than others." - Male CFO, Software development firm $(0 \%$ females in TMT) 
Figure 1. The Moderated-mediation Model of TMT Gender Diversity

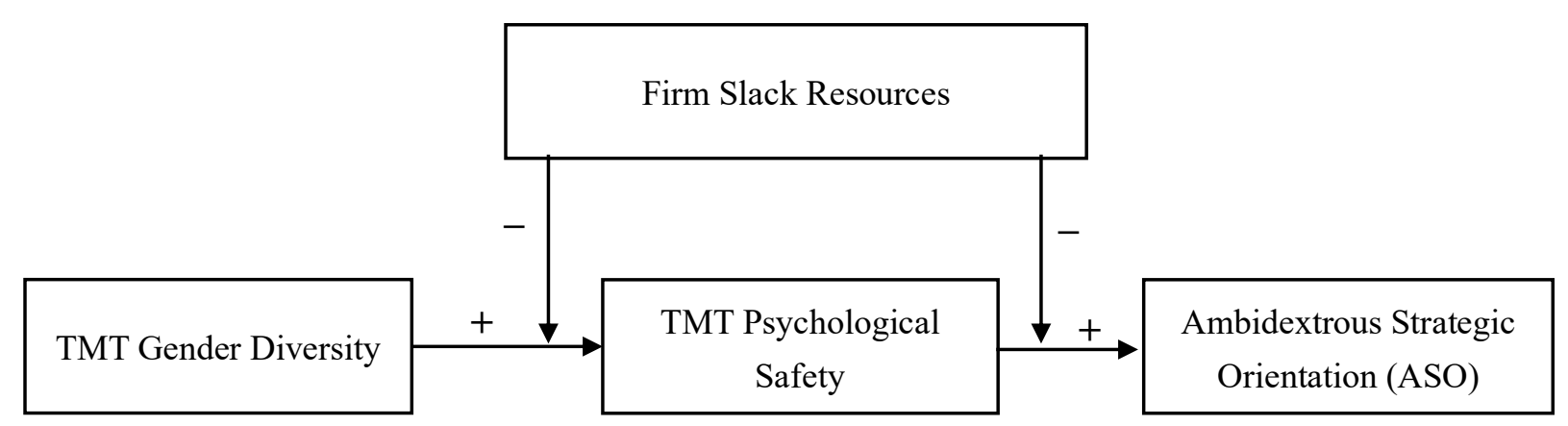


Figure 2. The Moderation Effects of Firm Slack on the TMT Gender DiversityPsychological Safety and TMT Psychological Safety-ASO Relationships

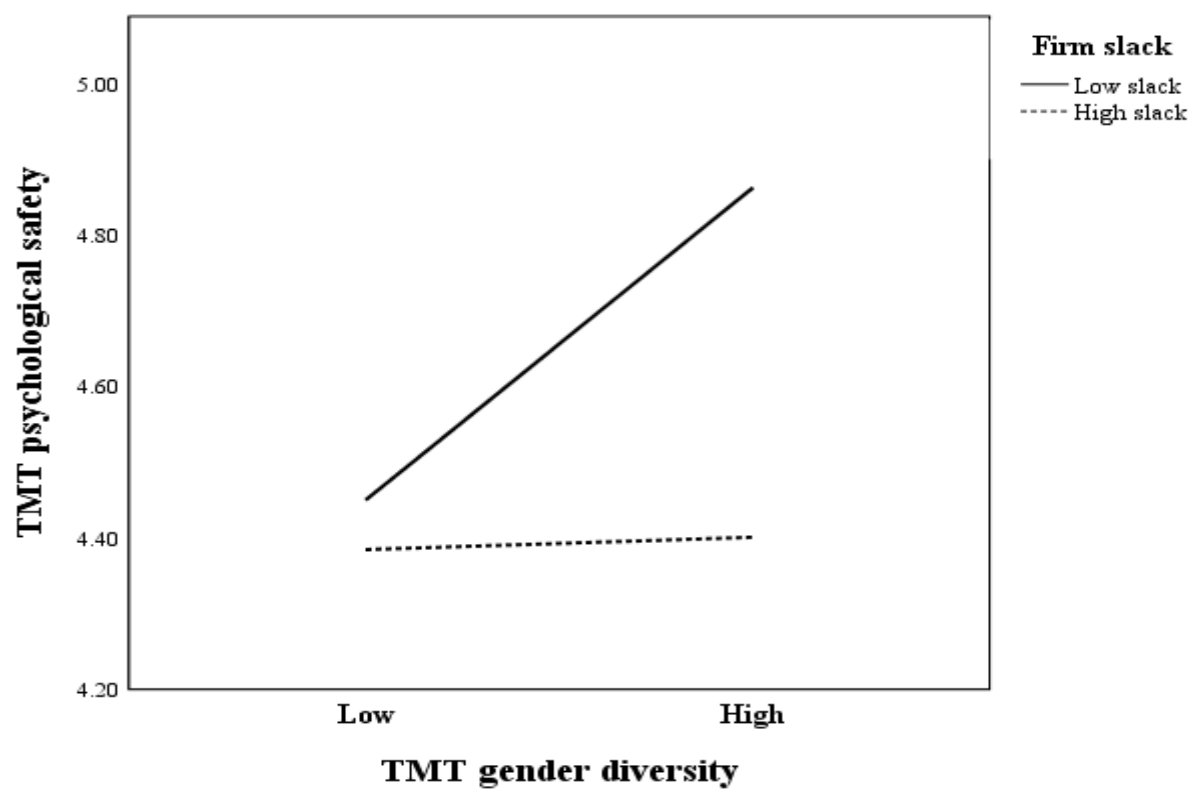

a. The effect of TMT gender diversity on TMT psychological safety conditional on firm slack

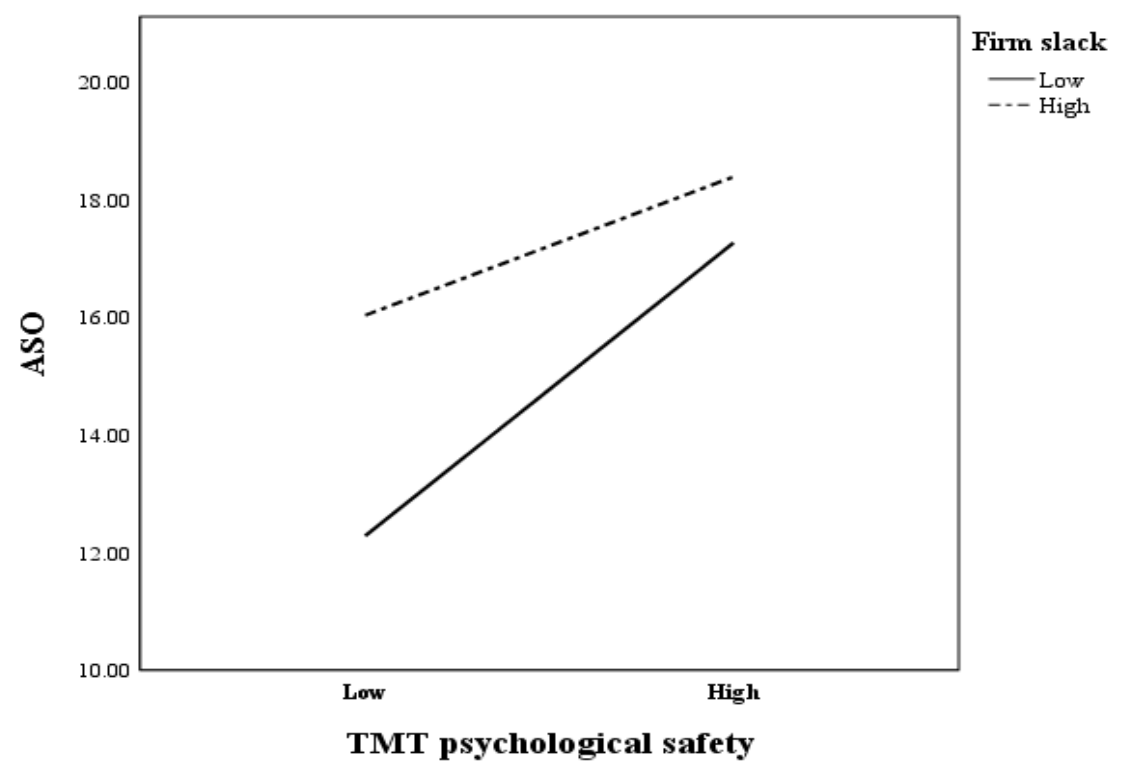

b. The effect of TMT psychological safety on ASO conditional on firm slack 


\section{Appendix I. Description of the Validation Study}

\section{Sample and Data Collection}

We sent an online Qualtrics survey to the top managers of 450 randomly drawn firms from our target population of Chinese high-tech SMEs (not included in the sample of the main study). We received 219 complete responses (response rate: $49 \%$ ), with 45 percent of the responses from females. The top managers had an average age of 35 years and job tenure of 4 years. Their firms were 14 years old and had 74 fulltime employees on average. We found no significant difference in the individual gender $(t=.14, n . s$. $)$ or firm age $(t=-.60, n . s$. $)$ between responding and non-responding top managers.

\section{Measures}

We measured social sensitivity using "Reading the Mind in the Eyes" test developed by Baron-Cohen et al. (2001) (all materials of this test are available at https://www.autismresearchcentre.com/arc_tests). This test has been widely used to assess individuals' general social sensitivity that can be applied across different settings (e.g., work groups, Woolley et al., 2010). The top managers were presented with photographs capturing the eye-region of different actors and actresses, and were asked to choose from four given words to best describe what the person in each photograph was feeling. The photos capture complex emotional states, with equal numbers of male and female faces. We measured voice-raising tendency by a 6-item scale $(1=$ strongly disagree to $7=$ strongly agree $)(\alpha=.76)$ adapted from Van Dyne and LePine's (1998) original scale for work team settings. We modified the referent from "this work group" to "this top management team." An example item is "I communicate opinions about work issues to others in this top management team even if my opinion is different, and others in the team disagree with me." We controlled for individual (age, job tenure, education and functional background), firm (firm size, firm age) and industry (sector dummies) factors that could serve as alternative explanations of variations in the social sensitivity and voice-raising tendency (Joshi \& Roh, 2009; Van Dyne \& LePine, 1998; Williams \& Polman, 2015).

\section{Analysis and Results}

We first used multiple analysis of covariance (MANCOVA) to estimate the effect of gender on the two interpersonal proclivity variables (i.e., social sensitivity and voice-raising tendency) as a set. Results of MANCOVA indicate an overall significant effect of gender on these social role-based interpersonal proclivities, Wilks' Lambda $(\lambda)=.76, F=29.55, p<.01$. Then, we conducted the analysis of covariance (ANCOVA) using the same controls to examine the effect of gender on social sensitivity and voice-raising tendency, respectively. The ANCOVA results show that women (adjusted mean $=6.04$ ) have significantly higher social sensitivity than men (adjusted mean $=4.77$ ): $F=28.21, p<.01$, partial $\eta^{2}=.13$. In contrast, men (adjusted mean $=5.80$ ) have significantly higher voice-raising tendency than women (adjusted mean $=5.47), F=16.03, p<.01$, partial $\eta^{2}=.08$. The effect sizes of gender differences in both proclivities are adequately large (above the recommended level of .06, Cohen, 2013). These results support our theoretical premise that female and male top managers in SMEs differ in their social role-based interpersonal proclivities - women are more socially sensitive, and men have higher voice-raising tendencies. 
Appendix II. Testing for curvilinear indirect effect of TMT female percentage on ASO via TMT psychological safety

For nonlinear mediation models, Hayes and Preacher (2010) introduced the instantaneous indirect effect $(\theta)$ to quantify the change in the DV through a mediator as the independent variable changes by one unit at a specific value. We specified the path from TMT female percentage to TMT psychological safety as quadratic, and the path from TMT psychological safety to ASO as linear (Table A shows the regression results). Based on 10,000 bootstrap samples, we estimated the instantaneous indirect effect (TMT female percentage $\rightarrow$ TMT psychological safety $\rightarrow$ ASO) at different levels of TMT female percentage $(30 \%$, $50 \%$ and $70 \%)$.

The results showed that when TMT female percentage is low (e.g., $30 \%), \theta(=1.57,95 \% \mathrm{CI}=[.01,3.47])$ is significantly positive, meaning that ASO increases via TMT psychological safety as TMT female percentage increases until it reaches around 50 percent. Once TMT female percentage reaches around 50 percent, $\theta$ is close to zero and insignificant $(=-.21,95 \% \mathrm{CI}=[-1.30, .81])$, meaning that ASO reaches the maximum and does not change via TMT psychological safety as the female percentage changes. When the female percentage is high (e.g., $70 \%), \theta(=-1.99,95 \% \mathrm{CI}=[-3.77,-.64])$ is significantly negative, meaning that ASO decreases via TMT psychological safety as the female percentage increases beyond the threshold of 50 percent.

Table A. Results of OLS regressions of TMT female percentage on TMT psychological safety and ASO $^{\text {a }}$

\section{Controls}

TMT heterogeneity

TMT tenure diversity

CEO age

CEO-TMT power distance

Firm past performance

Firm size $(\log )$

Firm age

Prior $\mathrm{ASO}^{\mathrm{a}}$

Industry sector

\begin{tabular}{cccc}
\multicolumn{4}{c}{ TMT Psychological Safety } \\
\hline $\boldsymbol{B}$ & $\boldsymbol{S E}$ & $\boldsymbol{B}$ & $\boldsymbol{S} \boldsymbol{E}$ \\
-.01 & .03 & -.002 & .02 \\
.08 & .31 & .10 & .30 \\
$.02 *$ & .01 & $.02 *$ & .01 \\
-.02 & .03 & -.02 & .03 \\
-.08 & .05 & $-.10 \dagger$ & .05 \\
-.03 & .05 & -.03 & .05 \\
.02 & .03 & .02 & .02 \\
$.03 *$ & .01 & $.03 *$ & .01 \\
YES & & YES &
\end{tabular}

\begin{tabular}{cc}
\multicolumn{2}{c}{ ASO $^{\mathbf{a}}$} \\
\hline $\boldsymbol{B}$ & $\boldsymbol{S E}$ \\
-.16 & .16 \\
1.96 & 1.90 \\
.06 & .05 \\
.09 & .20 \\
.25 & .31 \\
$-.87 * *$ & .32 \\
$.33 *$ & .16 \\
$.30 * * *$ & .08 \\
YES &
\end{tabular}

Main effects

Firm slack

TMT female percentage

TMT female percentage ${ }^{2}$

TMT psychological safety $\mathrm{F}$

Adjusted $\mathrm{R}^{2}$

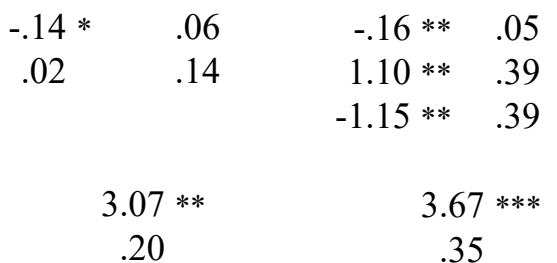

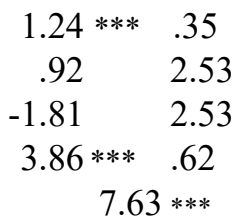

.54

$\mathrm{n}=120 . \quad p<.10$ (two-tailed); ${ }^{*} p<.05$ (two-tailed); ${ }^{* *} p<.01$ (two-tailed); ${ }^{* * *} p<.001$ (two-tailed).

a. ASO: ambidextrous strategic orientation 
Shi Tang (st637@cam.ac.uk) is currently a PhD candidate at Judge Business School, University of Cambridge. Her research focuses on gender in the upper echelons, executives' temporal orientation, top management team composition and dynamics, and strategic decision-making processes.

Sucheta Nadkarni (1967-2019) was the Sinyi Chaired Professor of Chinese Management in the Judge Business School, University of Cambridge. She received her PhD from the University of Kansas. Her research focused on executive personality and temporal orientation, strategic cognition, and competitive dynamics.

Li-Qun Wei (weiliqun@hkbu.edu.hk) is a professor of management in the School of Business, Hong Kong Baptist University. Her research interests include gender in executive leadership, top management team dynamics, strategic human resource management and Chinese business strategies.

Stephen X. Zhang (stephen.X.zhang@gmail.com) is an associate professor of entrepreneurship and innovation at the University of Adelaide. He studies how entrepreneurs and top management teams behave under uncertainties, such as the impact of major uncertainties in the contemporary world (e.g. COVID-19 and AI) on people's lives and work. Such research has also given Stephen opportunities to raise more than US\$1.5 million of grants in several countries. Prior to his academic career, Stephen has worked in several industries and has founded startups. 